\title{
7. Pescado itálico en el Impianto Elettrico Reflexiones sobre la filiación de las ánforas Dressel 21-22
}

\author{
Darío Bernal-Casasola y Daniela Cottica
}

\subsection{Introducción}

Durante los trabajos de catalogación del proyecto I.E. se localizaron algunas evidencias de ánforas de la familia de las Dressel 21-22, las cuales no eran muy abundantes desde el punto de vista cuantitativo, constituyendo apenas el 3,6\% del total de envases catalogados [369384]. Sin embargo, su relevancia es notable, ya que se trata de una familia tipológica a la cual se le ha prestado tradicionalmente poca atención, pero que ha cobrado notable importancia en los últimos años gracias a las numerosas reflexiones y avances sobre su caracterización, de la mano, eminentemente, de los estudios de E. Botte (2004, 2009c). Ello, unido a su contenido piscícola, que es uno de los objetivos monográficos de estudio del proyecto Pesca y Garum en Pompeya y Herculano (2008-2012), acometido por la Universidad de Cádiz y la Università Ca' Foscari de Venezia (Bernal, Cottica y Zaccaria 2008, 2010, 2011; Bernal et al. 2012) han planteado la conveniencia de separarlas de las demás producciones sincrónicas, y otorgarles un tratamiento monográfico, que desarrollamos en estas páginas.

El objetivo de este trabajo es triple. En primer lugar procederemos a realizar un estado de la cuestión de la problemática de las ánforas Dr. 21-22 y de los avances en su conocimiento producidos en los últimos años, haciendo alguna propuesta nueva, como es la de la ampliación del intervalo cronológico de vida de esta familia; en segundo término presentaremos las evidencias de esta tipología recuperadas con motivo del proyecto de catalogación de materiales del I.E.; y, en tercer lugar, realizaremos una reflexión sobre el modelo de exportación y aprovisionamiento de pescado en salazón a Pompeya en función de los resultados de este estudio, incidiendo en algunos aspectos novedosos sobre esta tipología de envases itálicos: se sintetiza la reciente verificación arqueológica y arqueozoológica del contenido piscícola de las Dr. 21/22 a través de los hallazgos en la Tienda del Garum de Pompeya (2008-2012); asimismo, se planteará la problemática de los talleres occidentales productores de ánforas afines a las Dr. 21/22, valorando la existencia de dos posibles focos de producción (en el área costera de la Tarraconensis y en la costa mediterránea de la Hispania Ulterior -bahía de Algeciras y litoral gaditano-) y discutiendo las relaciones de estas formas con las Dr. 2122 itálicas; en este contexto, se planteará un análisis de la distribución de estas ánforas por el Mediterráneo Central y Occidental, zona por antonomasia de difusión de estos envases. Y, por último, y más con preguntas que con respuestas, se evaluará nuestro conocimiento sobre otros envases (anfóricos y de otra naturaleza) relacionados con la comercialización de los salsamenta itálicos, así como de la confluencia de ánforas salazoneras de diversas provincias mediterráneas en los mercados de Pompeya desde época tardorrepublicana e inicios del Alto Imperio, compitiendo con la importancia y fama de las conocidas ánforas de salazón hispánicas.

Este capítulo tiene como objetivo fundamental contribuir al estímulo de los estudios sobre la industria pesqueroconservera del área vesubiana en sentido amplio, y evaluar la importancia del pescado y de su consumo tanto en la dieta pompeyana como en la economía cotidiana de las ciudades campanas durante época imperial.

\subsection{De las Dr. 21-22. El redescubrimiento de una familia de ánforas salazoneras itálicas}

Las ánforas Dr. 21-22 han constituido durante décadas el paradigma de los envases destinados a la comercialización delafruta en conserva, habiendo aceptado la investigación las sugerentes interpretaciones de H. Dressel en relación a los tituli picti, indicativos de manzanas de Cumas (mala cumana) y de las cerezas (cerasa) o de algún tipo de ciruelas (cerinae), procedentes básicamente de Roma y de Pompeya (un ejemplo de cada caso en C.I.L. XV, 4783 y 4788, Dressel, 1879: 166-172). Trabajos de investigadores como M.H. Callender (1965) o F. Zevi (1966) en los años sesenta aceptaron y ratificaron estas atribuciones, dando por válida la lectura y desarrollo de las citadas inscripciones.

Así quedó 'institucionalizada' dicha atribución, y durante décadas, desde el despertar de la anforología en los años setenta y setenta del siglo pasado a la actualidad, estos envases itálicos han permanecido vinculados al transporte y venta de fruta en conserva. Basta una consulta en los principales manuales de clasificación de la disciplina, tanto en los años ochenta - 'principal content: fruit'(Peacock y Williams 1986: 96-97)- como en los noventa -produit transporté: fruits (?)- (Sciallano y Sibella 1991: 37, fiche amphore Dressel 21-22), hasta la base de datos de Southampton, en la cual se considera que entre otros alimentos pudo haber transportado manzanas, cerezas y miel, planteando que la versión hispánica -sobre la cual volveremos más tarde- pudo haber contenido garum (University of Southampton, 2014).

Consideramos importante destacar que uno de los primeros investigadores que plantearon el posible contenido salazonero del envase Dr. 21-22 fue M. Beltrán, 


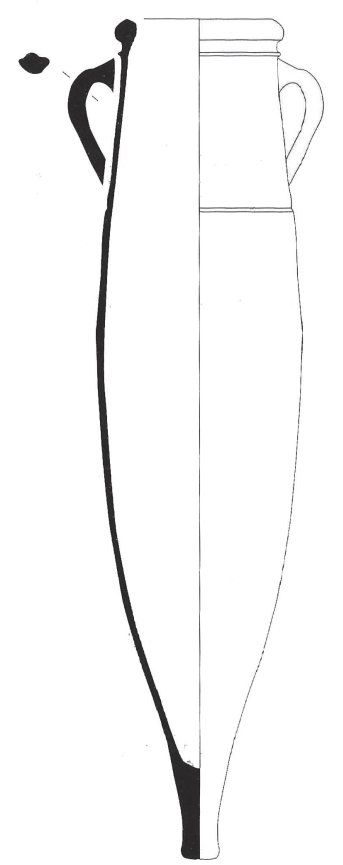

Type 1a

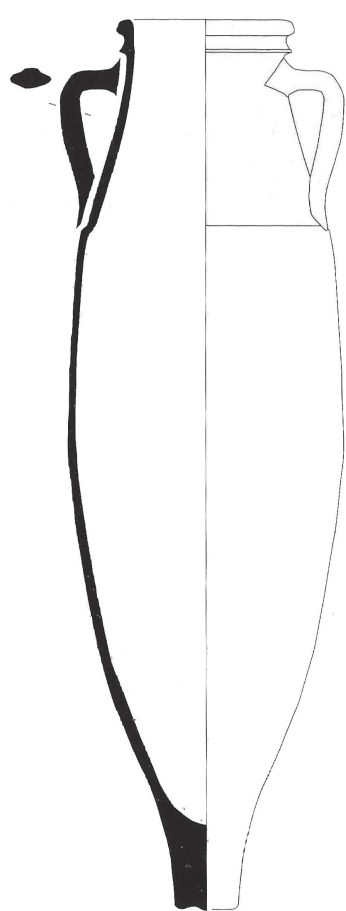

Type $1 \mathrm{~b}$

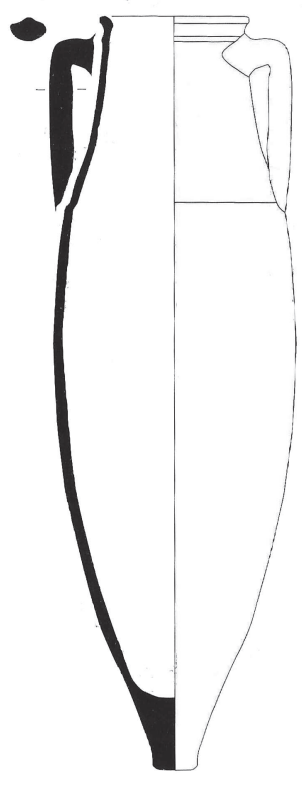

Type 2

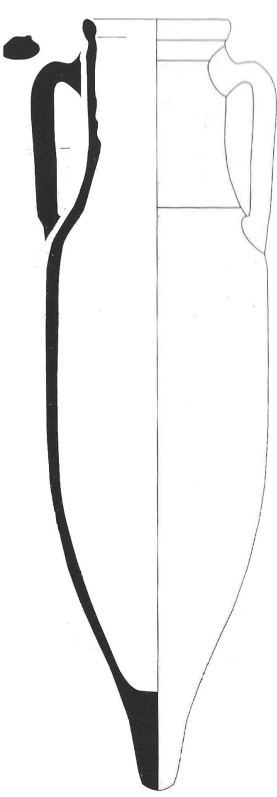

Type 3

Figura 1. Tipología de las Ánforas Dressel 21-22 Según Botte (2009c: 160, Fig. 4-45).

quien argumentó en su momento dos ideas: la vinculación a este tipo a un titulus que mencionaba Liq(uamen) F(los) Exce(llens), Scom(bri), C. CORNELI HERMEROTIS, MA DE DOMESTICI (CIL IV, 5716); y la presencia en él del nombre de dicho mercator -y de otro en otra inscripción similarque únicamente aparecían negociando con ánforas salazoneras, admitiendo eso sí, un contenido vinculado con las frutas en conserva (Beltrán 1970: 513, nota 1171 y 1172).

Casi sin novedades significativas llegamos a momentos avanzados de la primera década del s. XXI, momentos en los cuales investigadores del Centre Jean Bérard de Nápoles comenzaron la revisión del anforario de Pompeya, en una dinámica de estudio del artesanado vesubiano y de las excavaciones en la cercana ciudad de Cumae. Dichos estudios han cristalizado en la revisión por completo de esta familia anfórica a través de una Tesis Doctoral, desde algunos trabajos previos centrados en la problemática tipo-cronológica (Botte 2007, 2009a, 2009b) y en dar a conocer una inscripción inédita procedente de CVMAE (Botte 2008), a una monografía específica que trata el tema de manera detallada, aunando datos epigráficos, tipológicos, textuales y arqueométricos (Botte 2009c).

No vamos a resumir aquí y ahora estas investigaciones, ya que se han destinado muchos y valiosos esfuerzos a ello en los últimos trabajos citados, actualizando progresivamente en ellos las novedades. Nos limitamos únicamente a sintetizar aquellos aspectos básicos derivados de la tipología, las áreas de producción, la cronología y el contenido.
Desde un punto de vista tipológico, son las formas que se corresponden con los tipos que a lo largo del tiempo han sido denominados progresivamente como IV de R. Schoene, XLIII y XLIV de A. Mau, Dressel 21-22, Ostia LIV y también Peacock-Williams class 7 , y que englobaban una diversidad formal notable, de ahí que se decidiese en su momento hacer una nueva propuesta de tipología (Botte 2004). Dicha propuesta se articula en la definición de tres formas, que ilustramos en la Figura 1.

La forma Botte 1 presenta variantes a y b, y su producción en Sicilia ha sido confirmada recientemente para la variante 1a gracias a la localización y excavación de un taller en Alcamo Marina -Castellamare del Golfo, área de Trapani-, ${ }^{1}$ en el cual se conoce un sello in collo $\mathrm{F}(. ..) / \mathrm{A}(. .$. asociado a esta forma (Giorgetti, González y Botte 2006), aunque no se excluye que fuese producido en otras áreas del Latium y la Campania septentrional, para lo cual no hay confirmación actualmente (Botte 2009c: 131). Presenta una característica panza en 'obus' con asas poco desarrolladas y pivote macizo apuntado, características generales que hereda de las ánforas púnicas de producción siciliana, como las de las series 4 y 7 de J. Ramon (1995). La variante $1 \mathrm{~b}$ difiere sustancialmente de la anterior, presentando múltiples similitudes con el tipo 2, y para ella, atendiendo a criterios mineralo-petrográficos, se ha

\footnotetext{
${ }^{1}$ Se ha propuesto la existencia de dos variantes morfológicas de este tipo en dicha figlina, en función de parámetros métricos (Alcamo B y la versión más pequeña o Alcamo A), y a su vez tres tipos fechados respectivamente entre Augusto-Claudio, Nerón y de la segunda mitad del s. I d.C., posibles indicios de la evolución tipológica de la forma, al menos en dicho centro de producción (González Muro 2011).
} 
propuesto asimismo una producción siciliana, existiendo indicios de una posible manufactura en Solunto (Botte 2009c: 132 y 135). Respecto al contenido de esta forma, se han propuesto salazones piscícolas, valorando su frecuente hallazgo en el entorno de factorías de salazones en la costa occidental de Sicilia e interpretando las frecuentes inscripciones pintadas CE o CET que presenta como Cetus, considerando que se trataría de peces de gran tamaño, quizás atunes de notable porte, introducidos en tacos salados -salsamenta- debido al notable diámetro de las bocas, incompatibles con salsas líquidas (Botte 2009c: 128 y $131-132)^{2}$

La forma Botte 2 es de dimensiones algo menores, siendo muy característica la carena entre la panza y el cuello, y el notable desarrollo de las asas, que son muy alargadas y de sección oval, normalmente con múltiples acanaladuras dorsales. El pivote de nuevo es macizo y apuntado, y de dimensiones reducidas. A pesar de no conocer talleres de producción, los análisis mineralopetrográficos realizados por $\mathrm{C}$. Capelli han permitido proponer un área de producción en torno al estrecho de Mesina, posiblemente en la orilla peninsular, ante la ausencia de las características inclusiones volcánicas del Etna (Botte 2009c: 137). Se conoce el sello MVM in collo procedente de Pompeya (Botte 2009c: 137, fig. 4-25), al cual se han sumado recientemente HICVR y AEI -este último de compleja lectura- ${ }^{3}$ (Bernal et al. 2014a: 224, fig. 5 ánfora A09 y A054). En último lugar citar la reciente publicación de un sello fragmentario in collo, con lectura parcial $\mathrm{MA}(. .$.$) o \mathrm{AM}(. .$.$) , procedente de unos estratos$ fechados entre el 70-80 d.C. de las Terme del Nuotatore en Ostia -considerado por el autor como del tipo Botte 3- (Rizzo 2014: 149, Ostia VI, 63).

Respecto a los tituli picti, a esta forma se han asociado seis palabras abreviadas en el registro asociado al contenido, tratándose de CET, COP, SP, $A B, M A L$ y $V R$, restituidas respectivamente como cetus -atún-, cop(adium) -tacos de pescado salado-; S(a)p(erda) o sp(arus) -pescado indeterminado de la familia de los espáridos-; (f)ab(er) - pez de San Pedro- o ab(domina) -ventresca de atun-; MAL(akoi) -moluscos- o MAL(thé), posiblemente un gran escualo; y V(inum) R(ubrum) o ur(aeum) -fragmento de la cola del atún-, propuestas que han servido para proponer un contenido íctico para este tipo (Botte 2009c: 138-142, 152 y 145).

Por último, la forma 3 constituye un tipo claramente 'romano', con una carena muy marcada que permite una nítida diferenciación entre la panza y el cuello, con

\footnotetext{
${ }^{2}$ La confirmación de un contenido piscícola para estos envases se ha producido en las recientes excavaciones en la Tienda del Garum de Pompeya (Bernal, Cottica y Zaccaria 2010, 2011), sobre las cuales volveremos en el punto 4 de este capítulo de manera monográfica.

${ }^{3}$ Es posible que a esta forma se asocien otros sellos además de los aquí citados. En la base de datos CEIPAC se incluyen dos referencias al sello MAESTANE procedentes de Sicilia - Sirignano (CEIPAC 34106) y Alcamo Marina (CEIPAC 34105), además de referencias a otros en producciones hispánicas sobre los que volveremos más adelante.
}

unas amplias asas de trayectoria vertical, molduradas al exterior. El tipo se identifica muy bien por la boca, que posee un amplio borde destacado y notablemente moldurado, el cual además presenta una morfología muy variable entre unas ánforas y otras. Los análisis petrográficos han verificado la existencia en algunos ejemplares de piroxenos y feldespatos característicos de la región volcánica del Tirreno comprendida entre la Toscana meridional y la Campania, habiéndose definido al menos tres grupos de pastas correspondientes con al menos otros tantos talleres en el área lacial o campana (Botte 2009c: 146). Se conocen al menos dos sellos asociados a la producción itálica, siempre in labro: el primero CEIONI MAXIMI, documentado al menos en seis ocasiones -dos en Pompeya, Cumas, Monte Iato, ${ }^{4}$ Catania y Cartago- (Botte 2009c: 148-150, fig. 4-34); y por otro lado POST CVR (CEIPAC 25051; Botte 2009c: 146), a veces POST CVRT (en Éfeso sobre el borde de un ánfora de esta tipología), un personaje que fue identificado inicialmente como Caius Rabirius Postumus, tratándose de un político conocido en epigrafía anfórica de otras ánforas itálicas del tipo Dr. 2-4, brindisinas y en material constructivo latericio (Manacorda 1989: 451, nota 32 con bibliografía adicional); en fechas más recientes se ha asociado con el sobrino del anterior (adoptado por él entre el 63 y el 54 a.C.), Marcvs Curtius Postumus, un personaje conocido por las citas de Cicerón, Apiano, Flavio Josefo y Horacio, banquero en origen, especialmente activo entre los años 60 y 40 del s. I a.C. (Bezeczky 2006, y recientemente, Bezeczky 2013: 125 y 213-217 con la historia detallada y su cursus honorum). Actualmente conocemos este tipo de sellos en Dr. 1B, Dr. 2-4 y en Dr. 21-22 (Bezeczky 2013: 215216 con la revisión bibliográfica), no planteando dudas los recientes ejemplares publicados de Éfeso, de que se corresponden con cuellos del tipo Botte 3, uno de ellos sellado (Bezeczky 2013: 216 y nํ 308), fechados entre el 30/27 a.C.- 3 a.C. hasta el 23 d.C. (Bezeczky 2013: 124).

Por último, indicar que la citada monografía de Éfeso, de reciente aparición, incluye cuatro sellos anepígrafos en las asas (una letra G o símbolo; y un ancla o un símbolo en tres ocasiones), que por tipología y macroscopía de las pastas se insertarían en este grupo. En un caso se ha confirmado que se trata del tipo Botte 3, al conservarse el cuello y la boca del envase (Bezeczky 2013: pl. 29, no 318 y, 311,319 y 320), tratándose de los primeros sellos in ansa $\mathrm{y}$ no in collo/in labro como es frecuente en esta forma. Si se acepta la identificación de este personaje, sería posible retrotraer el origen de esta forma a mediados de los años 50 del s. I a.C. que es cuando conocemos sus referencias en el juicio de Cicerón, lo que aparentemente no cuadraría con el inicio 'canónico' de la cronología para esta forma, propuesto en época augustea (Botte 2009c: 148).

Respecto al contenido propuesto para este tipo, se asocian con el mismo tres tituli, CET, MAL y MIXST; para

\footnotetext{
${ }^{4}$ Un ejemplar de Monte Iato sellado y de pasta campana ha sido publicado recientemente (Palaczyk 2014: 582, no 1, Abb. 1, nº 5 y 6), junto a otros 33 ejemplares del tipo 1B y de pasta aparentemente siciliana.
} 
el primero ya hemos indicado la propuesta de identificar atún de Cumas (cetus); para Mal se propone bien malakoi (moluscos) o quizás con más posibilidades malthé (un gran escualo); y, por último, tras MIXST quizás se esconda mixtus, un preparado mezclado; también se citan otras inscripciones como la ya conocida AB, SP, COP, VR y SCOM (Botte 2009c: 150-153). Respecto a la zona de producción, tanto por la petrografía como por las inscripciones pintadas (adjetivos 'cumano/a' asociados a diversos de los productos) se ha propuesto un origen campano para el tipo, y más específicamente de la ciudad de Cumas (Botte 2009c: 158). Aunque es evidente que la diversidad tipológica y de pastas debe esconder tras de sí diversas regiones productoras y múltiples talleres.

Para la definición de áreas de producción, remitimos a la caracterización mineralo-petrográfica realizada por C. Capelli y otros colegas, que define 3 grupos sobre el material analizado (Grupo 1 - cuarcítico fino; Grupo 2 - metamórfico; Grupo 3.- volcánico), que asocia respectivamente con Sicilia Occidental, con el área calabro-peloritana (Calabria meridional y Sicilia NE, sin elementos volcánicos, por ello más posiblemente peninsulares) y con el área tirrénica (Toscana meridional y Campania) (Capelli, Cabella y Piazza 2009: 164-168); y a los cuatro grupos petrológicos definidos para las Dr. 2122 de Éfeso (Fabrics: C1, J, J1 y K), de los cuales los tres últimos se asocian respectivamente con el área de Capua (con dudas), con la Campania y con Calabria (Bezeczky 2013: 126-127).

Esta nueva tipología ha clarificado muchos aspectos, si bien quedan algunas líneas a desarrollar en las próximas investigaciones. Nosotros planteamos dos aspectos tipológicos como los más significativos a clarificar en futuros trabajos:

- Valorar la pertinencia de mantener la clasificación de la variante $1 b$, pues la misma es muy similar tipológicamente a las ánforas del tipo 2, de las cuales prácticamente no se diferencian.

- Realizar un estudio en detalle del tipo Botte 3, en el cual se incluyen formas muy diversas entre sí, tanto tipológicamente como en lo que respecta a las posibles áreas de producción (diversidad macroscópica de pastas).

- Planteamiento de una posible evolución tipológica dentro de cada una de las formas, al haber sido producidas durante más de un siglo.

En relación a la cronología de esta familia, desde los pioneros trabajos de Castro Pretorio se tenía clara la filiación de las Dr. 21-22 en el s. I d.C., como hallazgos posteriores vendrían a demostrar -como por ejemplo el ánfora de Zaragoza de la primera mitad de esta centuria(Beltrán 1970: 511, fig. 205, 1). De manera que ésta (s. I d.C.) ha sido la cronología asociada a estas formas, desde F. Zevi a los tradicionales manuales de clasificación (Peacock y Williams 1986: 97; Sciallano y Sibella 1991:37).
El inicio del intervalo de producción se amplió, utilizando algunos depósitos estratigráficos (como La Longarina en Ostia) al último cuarto del s. I a.C. (University of Southampton, 2014).

La precisión tipocronológica de E. Botte ha permitido reflexionar recientemente sobre el intervalo datacional para cada una de las tres formas (2009c: 131-132, 135 y 145), teniendo presentes especialmente los contextos de Pompeya y Cuma, siendo la propuesta la siguiente:

- Tipo 1 A (1-100 d.C.) entre inicios (depósito augusteo de La Longarina en Ostia y rue de la Favorite en Lyon) y finales del s. I (79 - Pompeya y depósito flavio pre - 95 en Cumas), considerándose los hallazgos de época trajanea y antonina de Settefinestre como residuales; el Tipo $1 \mathrm{~b}$ estaría siendo producido claramente en época flavia por citados hallazgos de Pompeya y Cumas.

- Tipo 2 (25 a.C. - 125 d.C.) - desde el último cuarto del s. I a.C. (hallazgo en la Casa del Porche de Ostia) -que el autor rebaja sobre la cronología inicial establecida entre el 50-25 a.C.- hasta los primeros decenios del s. II d.C. (Botte 2009c: 145), aunque recoge una Dr. 21-22 del pecio de Grado fechado a mediados del s. II d.C. (Auriemma 2000: 40, fig. 11).

- Tipo 3 (25 a.C. - 100 d.C.) - Un ejemplar de Masada se ha fechado entre el 37-4 a.C., siendo el más antiguo del tipo; mientras que los más modernos son los ya citados de Cumas y de Pompeya de época flavia (último cuarto del s. I d.c.).

A la luz de estas evidencias, consideramos importante plantear los siguientes aspectos respecto al intervalo tradicionalmente atribuido a esta forma.

Aunque no es posible por el momento demostrarlo con materiales estratificados, es muy probable que el inicio de la producción de las Dr. 21-22 haya que atrasarlo un poco en el tiempo, posiblemente en torno al año 50 a.C. o quizás incluso algunas décadas antes. ${ }^{5} \mathrm{~A}$ favor de dicho origen anterior a época augustea tendríamos los datos ya comentados de los sellos de Postumus Curtius, relativos al personaje histórico que mantuvo buena parte de su actividad en dichas fechas; o las referencias al pecio siciliano de 'Scoglio delle Formiche A', cerca de Solunto, cargado con ánforas tunecinas y fechado tradicionalmente en el s. II a.C. (Parker 1992: 390, nº 1052), habiendo sido redatado a mediados del s. I a.C. (Bezeczky 2013: 126), aunque está pendiente de verificación. Si así fuese tendría mayor explicación la aparente ausencia de ánforas salazoneras sicilianas entre época de Sila y de Augusto: los envases haliéuticos del tipo 'Tubular Amphora' se fechan actualmente entre el 150 y el 80 a.C., existiendo un vacío entre ellas y las primeras Dr. 21/22, que se plantea explícitamente (Botte 2013:599, fig. 8 y 603-

${ }^{5}$ Una fecha similar (50/25 a.C.) ha sido utilizada por otros investigadores
para la clasificación de los materiales de Roma (Rizzo 2003: 145 y 161). 


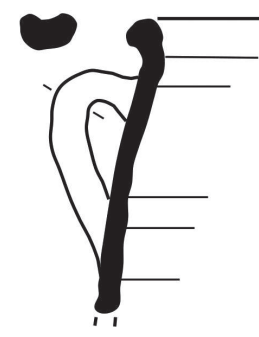

A

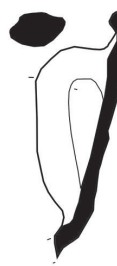

Figura 2. SELECCIÓN DE DR. 21-22 de CONTEXTOS DEL S. II D.C., PROCEDENTES DE OSTIA (A Y B. RIZZO 2014: TAV. 10, № 65 Y 66), DE ROMA (C Y D. FERRANDES 2008: no 43 y 44) Y DEL PECIO DE Grado (AURIEMma 2000: 38, FIG. 11).
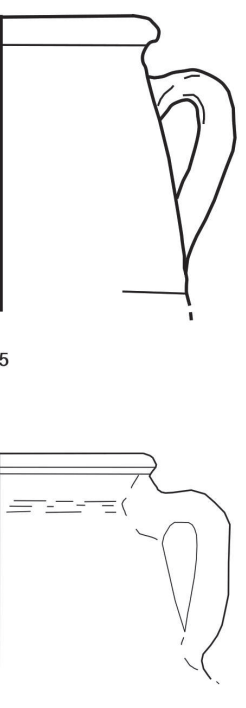

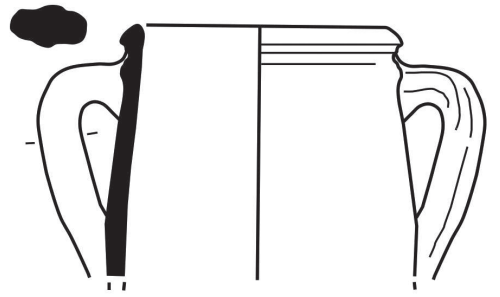

B

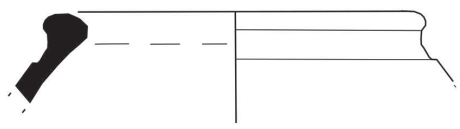

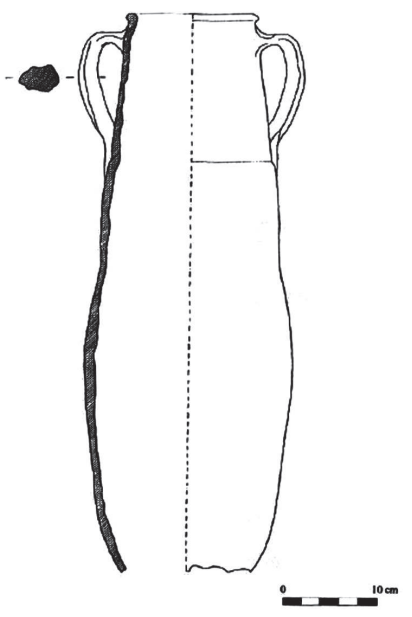

604; Pascual y Ribera 2014). No olvidemos que el s. I a.C. es una época de continuas experimentaciones en ámbito provincial -momento de cristalización, por ejemplo, de las series ovoides del Valle del Guadalquivir-, y por ello no extrañaría que así lo fuese también en la Italia tirrénica $\mathrm{y}$ en Sicilia. Lo que podemos intuir por el momento es que las mejores candidatas a ser las primeras en aparecer en los mercados, si es que no aparecieron varios tipos al unísono, son las ánforas del tipo 3, que heredan muchos detalles de las Dr. 1, con el borde en banda ('bourrelet' o 'a fascia'), o la costumbre del sellado in labro.

En segundo término, consideramos que existen suficientes evidencias como para proponer que el final de la producción de las Dr. 21/22 se produjo, al menos, en época antonina (150/175 d.C.). Como suele ser habitual en los procesos de definición tipo-cronológica de las formas, algunos ejemplos alejados de las dataciones mayoritarias provocan que sean considerados materiales residuales y descartados, como ha sucedido en este caso con los materiales de esta tipología aparecidos en Settefinestre o en Grado. A continuación incluimos algunos contextos terrestres con materiales de diversos lugares del Mediterráneo que permiten plantear la prolongación de la vida útil de las Dr. 21/22 durante buena parte del s. II d.C. (Figura 2).

En Italia, contamos con tres contextos de interés. Por un lado, en Ostia, los hallazgos en el área al NE delle Terme, han permitido recuperar varios fragmentos -al menos 14 bordes y 2 asas- de niveles fechados entre el 80-90 d.c. y especialmente de época tardo-antonina, prácticamente todos ellos del tipo Botte 1a (Rizzo 2014: 148; Ostia VI, tav. 10, 65-66 y 78-79), aunque dos bordes parecen asociarse al tipo Botte 2 (Rizzo 2014: 148, Ostia VI, tav. 10, 63-64). Esta constatación es importante, porque parece verificar la llegada a Ostia porcentajes muy similares de ambas formas $(3,38 \%$ y $3,05 \%$ respectivamente) a finales de época antonina (Rizzo 2014: 422).

Teníamos constancia también de la exportación a Roma de Dr. 21-22 en proporciones muy bajas, como demostraron diversos hallazgos en la Via Nova -en el 64 d.C.- y en la Meta Sudans -64-68 d.C.-, que para época neroniana constituían un $0,48 \%$ del total, porcentaje que se mantenía casi inalterado en época flavia (0,5\%) gracias a los contextos de la Via Nova, Crypta Balbi, el Forum Transitorium y, especialmente, Vigna Barberini- (Rizzo 2003: 
145-149, tabella 26a; y 161, tabella 27a). Recientemente este panorama se ha ampliado gracias a la constatación en época tardo-antonina de varios ejemplares del tipo 1A, procedentes del área del Gianicolo, de descargas fechadas entre mediados del s. II y el 170/180 d.C. (Ferrandes 2008: fig. 6, nº 43 y 44; a las que quizás podríamos añadir la pieza ilustrada en la figura 13, nº 153; Rizzo 2014: 148, nota 372).

En el caso del conocido pecio de Grado, en las aguas septentrionales del adriático, tenemos constancia de la recuperación de una Dr. 22 completa en la rueda de popa de la nave, hallazgo similar al de otros envases aislados (como los tipos Forlimpopoli o un ánfora de Cnidos) en un cargamento de pescado re-envasado en ánforas africanas (Africana IA, Tripolitana 1), orientales (Knossos A/53) y ánforas noritálicas fuertemente empegadas (Auriemma 2000: 38, fig. 11). Los citados materiales del cargamento y los elementos de la dotación de a bordo de la tripulación han permitido fechar el naufragio en los años centrales del s. II d.C., lo que ha llevado a los excavadores a plantear la posible perduración de la producción de las Dr. 21-22 hasta estas fechas. ${ }^{6}$ Este envase es claramente asimilable al tipo Botte 2 .

En Francia, tenemos constancia de la documentación de un borde de Dr. 21 del tipo 1 A de Botte en niveles fechados entre el segundo y tercer decenio del s. II (120140) por sigilatas africanas y africanas de cocina, clara B, lucernas y otros materiales en el Sector IV (Fase IV) de la zona al 'Nord-Est cathédrale' de Frejus (Rivet 2010: 108, fig. 95, no 444).

Los ejemplares de Dr. 21-22 del siglo II d.C. citados, que ilustramos parcialmente en la figura 2, parecen confirmar que al menos hasta el 150/175 la producción de estas ánforas salazoneras debió estar en activo, tanto en los talleres de Sicilia occidental (Botte 1) como en los calabreses - peloritanos (Botte 2), ya que ambas formas están bien constatadas en estas fechas. Aparentemente, o al menos a tenor de los ejemplares conservados, no se advierten diferencias tipológicas significativas respecto a sus antecesoras, más allá del carácter más masivo de las asas en sección y la posible amplitud del diámetro de las bocas, aspectos que habrá que intentar confirmar en el futuro cuando se disponga de una muestra significativa desde un punto de vista estadístico.

Por todo lo comentado, en el estado actual de la investigación proponemos que el intervalo de producción y comercialización de las Dr. 21-22 se produjo entre el 75/50 a.C. y el 150/175 d.C.

\footnotetext{
${ }^{6}$ 'Una circolazione, seppur limitata, ancora nella prima metà - metà del II sec. d.C., attestata dall'evidenza di Grado, potrebbe esser suggerita da un orlo proveniente da un contesto severiano delle Terme, considerato un resto molto più antico, e da un frammento rinvenuto in uno strato preadrianeo della casa delle Pareti Gialle ad Ostia: cfr. Zevi e Pohl 1970: 214, fig. 109, 216, ๆ. 660; Ostia I: 120; Ostia III: 496-497; Martin Kilcher 1993: 279 (per i contesti cartaginesi)' (Auriemmna 2000: 38, nota 28).
}

\subsection{Las ánforas del tipo Dr. 21-22 del I.E. Tipología y representatividad en los contextos pompeyanos}

Las ánforas itálicas documentadas en el proyecto Impianto Elettrico son muy numerosas, especialmente las de los tipos grecoitálicos y Dr. 1 (150 individuos), que capitalizan casi el 35\% del total. Por el contrario, las ánforas asimilables a la familia de las Dr. 21-22 son muy escasas, 16 en total, teniendo en cuenta los 13 bordes y fragmentos de boca $[\mathbf{3 6 9}-\mathbf{3 7 9}, \mathbf{3 8 1}, \mathbf{3 8 2}]$ y las tres asas atribuidas a esta tipología [380, 383, 384], lo que provoca que su presencia porcentual sea de aproximadamente el $3,6 \%$ del total.

A pesar de la complejidad cronológica de los contextos de procedencia del material y de la notable residualidad, este porcentaje podría parecer a priori muy reducido, aunque si lo comparamos con otros contextos no es así. En otros ámbitos pompeyanos la presencia de Dr. 21-22 parece asimismo reducida, como parece deducirse de su total ausencia en algunas ocasiones, como por ejemplo en las recientes intervenciones en el jardín de la Casa de Marco Fabio Rufo (Grimaldi et al. 2011: 17 y 18) o en la publicación de los resultados ceramológicos del proyecto Anglo-Americano en la Casa de las Vestales (VI,1,7), donde ni siquiera se menciona su existencia, frente a la gran variedad de mercancías transportadas en ánforas (De Sena y Ikaheimo 2003). Tampoco se referencian Dr. 21-22 en los trabajos acometidos en la Insula 5 de la Regio VI, en la cual se han estudiado las ánforas de manera monográfica (Scotti 1984). ${ }^{7}$ No obstante, es importante valorar que es muy probable que muchas publicaciones escondan tras de sí problemas de carácter metodológico, relacionados con la identificación de las formas en el registro, ya que las mismas son de definición relativamente reciente.

En algunos casos se citan hallazgos esporádicos en Pompeya, como sucede con un ejemplar de una Dr. 21/22 identificado en las recientes excavaciones de la Casa de Ariadna -campaña de 2007- (Pascual y Ribera 2007: 122) junto a un ánfora del tipo Botte 3 en un estrato de mediados del s. I a.C. -Sondeo A1, UE 1010/1- (Ribera 2007: 115), entre varios centenares de ánforas de época imperial. Por su parte, en la conocida casa I, 9, 12 - de Sextus Pompeius Amarantus-, muy citada por el hallazgo en su atrio de más de 75 ánforas cretenses apiladas de pie (llenas por tanto) durante la excavación realizada en los años 50 -además de algunas Dr. 2-4 itálicas y egeas-, en las recientes excavaciones inglesas se inventariaron 48 envases, divididos en 35 ánforas cretenses, 5 Dr. 2-4 itálicas y otras 5 de tipología indeterminada, a las cuales se uniría una Dr. 21-22 documentada en la documentación fotográfica de las antiguas excavaciones (Timby 2004: 385 y 386, fig. 4). Es decir apenas un ánfora Dr. 21-22 de un conjunto superior al centenar de ejemplares.

\footnotetext{
De poder relacionarse con esta familia algunos de los ejemplares publicados, serían un borde dudoso del tipo 1 -CE 394- y dos probables del tipo Botte 3 -CE1835/2 y CE 1092- (Scotti 1984: tav. 156, 10, 13 y 20).
} 
A vuela pluma, otro indicador es la cantidad de ánforas de la familia de las Dr. 21-22 conservadas en los depósitos de Pompeya de la Soprintendenza Speciale per iBeni Archeologici, claramente minoritarias - pues una parte proceden de la Tienda del Garum (I, 12, 8)- frente a los varios centenares de Dr. 2/4 itálicas -200 ejemplares, ya almacenados en las dependencias dei Granai del Foro en los años setenta (Panella y Fano 1977: 135; 2002)- o a los más de un centenar de ánforas conserveras hispanorromanas (Manacorda 1977).

Evidentemente el caso de la Tienda del Garum es un unicum, ya que en su interior se encontraban almacenadas más de un centenar de Dr. 21/22 dispuestas para ser reutilizadas en una esquina del patio trasero de la fábrica. De las 81 objeto de estudio durante las campañas de 2009 y 2011 de desmonte de la 'pila de ánforas', el 85,2\% eran calabresas (Dr. 21-22/Botte 2, 69 ejemplares), el 8,6\% campano-laciales (Botte 3, 7 ejemplares), siendo las procedentes de Sicilia occidental las minoritarias, con el 4,9\% del total (Botte 1, 4 items), junto a una Dr. 2-4 vesubiana aislada (Bernal et al. 2014a: 224, fig. 3). Evidentemente se trata de un depósito no representativo, al ser una fábrica-conservera y un lugar de venta de pescado al por menor, si bien sirve para ilustrar por primera vez la preponderancia de las diversas zonas productoras de estos envases en la ciudad vesubiana.

Por otro lado, en los contextos de exportación fuera del área vesubiana la presencia de Dr. 21-22 se sitúa como mucho en torno al 0,5\% del total, como ilustran los diversos contextos de Roma en época neroniana y flavia (Rizzo 2003: tabella 26 a y 27 a); en otras ocasiones la presencia es mayor, como en Altino, con el 2,3\% -cinco sobre 219 ejemplares publicados- (Toniolo 1991: 215), y el 1,5\% en el Ágora de Éfeso -74 sobre 4875- (Bezeczky 2013: 190, fig. 27), cifras que aún se reducirían más en los dos últimos casos citados si nos limitásemos a evaluar únicamente los envases altoimperiales.

En los demás contextos de consumo conocidos los hallazgos se limitan a importaciones de carácter esporádico y puntual (uno o varios ejemplares aislados), pudiendo por tanto plantear que el pescado siciliano o itálico constituye, en dichos casos, importaciones exóticas o de lujo, como ilustra, por ejemplo el ejemplar aislado de Dr. 21-22 de pasta campana documentado en las recientes investigaciones subacuáticas en el Ródano (Piton y Djaoui: 2009:264-265, nº 7), frente a los 37 envases de orígenes diversos. En dicho sentido, en la propia Sicilia se ha planteado recientemente que la importación de salsas de pescado puede considerarse un elemento de distinción social: así se ha planteado con las ánforas de este tipo en el Monte Iato, ya que en vez de consumirlas preferentemente de Alcamo Marina, el área más cercana, vendrían de Solunto (Palaczyk 2014).

En relación a la tipología a la cual se ajustan las ánforas del I.E., el carácter fragmentario del material dificulta las atribuciones, ya que no se ha conservado ningún ejemplar que supere los $10 \mathrm{cms}$ de altura total. La mayor parte de los bordes presentan su extremo superior sensiblemente exvasado y son de extremo superior redondeado, marcado al exterior por una característica sinuosidad en su pared, la cual provoca un doble resalte al exterior, dando paso a continuación a una pared rectilínea $[369,370,372,373$, $374,375,376,377,378$ y 379], una característica propia tanto del tipo 1B como del 2 de Botte; las dimensiones de la boca presentan tamaños medios, que oscilan entre los 14 [371] y más frecuentemente los $16 \mathrm{~cm}[369,370,378$ y 379], presentando en una única ocasión 17 [377] y 18 en dos [374 y 375]. Los $22 \mathrm{cms}$ de diámetro de la pieza documentada en el Taglio IIIb, US 5 [373] posiblemente derivan del fragmentario estado del ejemplar, que ha dificultado la toma de dimensiones. Se trata de valores que son más propios de la variante Botte 2, cuyas dimensiones oscilan entre los $15-16,5 \mathrm{~cm}$, frente a los 19-20,5 del tipo 1B (Botte 2009c: 160). De ahí que consideremos que estas diez Dr. 21-22 del I.E. se ajustan más bien al tipo 2, entre las cuales incluimos también la boca que presenta el borde son su remate superior excepcionalmente engrosado [370] y con el borde superior apuntado, que no encuentra paralelo alguno con las producciones campanas de borde en banda ni con las conocidas morfologías de Alcamo Marina, invasadas y con un engrosamiento externo (Giorgetti, González y Botte 2006: 510, figs. 11-15). A ellas cuales se suma el asa con múltiples acanaladuras dorsales [380], plana y de cinta y con muchas acanaladuras dorsales, que es característica precisamente de este tipo, con paralelos precisamente en Pompeya (Botte 2009c: 136, fig. 4-23, no 43165 y 43166). Este tipo de bordes son menos apuntados que otras variantes de esta forma recuperadas en Monte Iato (Palaczyk 2014: Abb. 3). Respecto a las pastas, como se puede documentar en el anexo gráfico, son muy homogéneas desde un punto de vista macroscópico, de colorimetría amarillenta, en una matriz con pequeñas vacuolas redondeadas muy frecuentes, y abundantes inclusiones de cuarzo y otros minerales heterométricos y oscuros, de naturaleza metamórfica. Coinciden apriorísticamente con el denominado 'Gruppo 2 (metamorfiti)', atribuido al área calabresa-peloritana (Capelli, Cabella y Piazza 2009: 164-165).

El siguiente grupo es el conformado por sendas bocas con amplios bordes en banda, desarrollados notablemente en altura en torno a los $5 \mathrm{~cm}$, característicos del tipo Botte 3. El primero de ellos [381] con una pared externa sensiblemente cóncava en su parte central; y el segundo [382] con el borde sensiblemente exvasado y rematado en su parte baja por un extremo apuntado. Ambos tipos de borde cuentan con paralelos respectivamente tanto en Pompeya (Bernal et al. 2014a: fig. 4, A67; Botte 2009c: 147, fig. 4-32, $\mathrm{n}^{\mathrm{0}} 26115$ ) como en Luni (Botte 2009c: 148, fig. 4-32, izda. respectivamente). En este mismo grupo incluimos dos asas, la primera de cinta con amplias acanaladuras dorsales [384], similar a las de las ánforas del pecio de Mljet en Croacia (Botte 2009c: 147, fig. 4-31, Ml.1); y la segunda de sección mucho más engrosada y con cierta concavidad, marcada por tres acanaladuras 
externas [383], muy similar al ejemplar ya citado de la Tienda del Garum de Pompeya (Bernal et al. 2014a: fig. 4, A67). Las pastas de todos estos ejemplares son fácilmente distinguibles macroscópicamente por la presencia de múltiples minerales brillantes de color negro y naturaleza volcánica -incluyendo traquitas y basaltos-, elementos que abogan por una manufactura campana para estas formas, integrándose en el definido como 'Grupo 3 (vulcaniti)' (Capelli, Cabella y Piazza 2009: 166).

Por tanto los materiales del I.E. han proporcionado una mayoría abrumadora de Dr.21/22 del tipo Botte 2 (12 individuos, el $75 \%$ del total), mientras que las demás ánforas se inscriben todas ellas entre las producciones campano-laciales del tipo Botte 3 (4 individuos, 25\% del total). Sorprende la total ausencia de ánforas sicilianas del tipo 1, presentes en la ciudad, aunque aparentemente, según los datos ya comentados de la 'Pila d'anfore' de la Tienda del Garum, son las menos abundantes.

En relación a los contextos de procedencia del material, la mayor parte procede del Taglio III o IIIB, localizado en la parte trasera del Templo del Foro, de diferentes unidades: III, US 1 [369, 371]; IIIb US 2 [380]; IIIb, US 3 [378, 379]; IIIb US 5 [370, 372, 373, 374, 375]; IIIb, US 21 [382]; con algunos ejemplares aislados del Taglio IV, US $17 b$ [376 y 383], del V, US 7 [381], y del Taglio VIb, tanto de la US 12 [384] como de la US 23 [377]. Sorprende esta concentración de materiales exclusivamente en la zona occidental y septentrional del área foraria de Pompeya.

\subsection{De la verificación del contenido piscícola de las Dr. 21/22: excavaciones en la Bottega del Garum de Pompeya (2008 - 2012)}

Como hemos sintetizado con antelación, los trabajos de los últimos años han propuesto con bastante verosimilitud la posibilidad de que las ánforas de la familia Dr. 21-22 sean envases destinados al almacenaje de pescado en salazón, tratándose de una sugerente hipótesis de trabajo. Precisamente en relación a los contenidos, el propio E. Botte comentaba explícitamente que 'aucune découverte archéologique n'a permis de déterminer avec certitude le contenu des amphores Dressel 21-22' (2009c: 120).

Durante el año 2008 se inició el proceso de estudio de la Garum Shop de Pompeya, como parte de un programa de investigaciones sobre el papel del pescado y las conservas marinas en las ciudades vesubianas, del cual se han dado algunos avances, tanto de las cuatro campañas de campo realizadas como del proyecto en su conjunto (Bernal, Cottica y Zaccaria 2008, 2010, 2011; Bernal et al., 2012, 2014b). Actualmente está en proceso de estudio toda la documentación del proyecto de cara a la edición de los resultados, de los cuales adelantamos a continuación algunos datos inéditos.

Una de las actuaciones más singulares ha sido el estudio integral de la conocida como 'pila d'anfore', una acumulación cercana al centenar de ánforas casi exclusivamente del tipo que nos ocupa, situada en el segundo patio de la tienda, recién vaciadas, casi todas ellas con tituli picti, y apiladas en tres filas en altura pendientes de un ulterior tratamiento (Bernal et al. 2014a).

Durante el proceso de desmontaje de la pila se documentaron multitud de ictiofaunas arqueológicas asociadas a las ánforas, permitiendo la verificación de su contenido piscícola justo antes del proceso de estudio de las mismas. Por un lado, contábamos con restos adheridos a las paredes de algunas de las ánforas, los cuales habían quedado casi mineralizados como resultado de las adherencias salinas y el paso del tiempo en ambiente aeróbico. En la Figura 3 hemos seleccionado un ejemplo de tres ánforas asociadas al tipo Botte 2, todas ellas con titulus pictus en cuyo primer registro -alusivo al contenido- se lee la palabra $S P$, que denotan las tres situaciones posibles: únicamente restos de escamas, las cuales presentan bastantes problemas de identificación taxonómica (Figura $3 \mathrm{~A}$ ); escamas asociadas a restos craneales de peces de dimensiones reducidas (Figura $3 \mathrm{~B}$ ); y los dos elementos anteriores unidos a vértebras (Figura 3 C), en este caso de peces de las familias Centracanthidae y Engraulidae. En varias ocasiones se documentaron restos de resina adherida aún a la pared y en contacto con los restos ícticos, como en el ánfora A72 (Figura 3D). El proceso de extracción de las ánforas permitió recuperar, asimismo, restos del paleocontenido original de las ánforas en pequeños depósitos sedimentarios situados bajo las bocas, que en algunas ocasiones se habían conservado en torno al pivote de las ánforas de la fila inferior, como al extraer el ánfora calabresa A72 que estamos utilizando de ejemplo (Figura $4 \mathrm{~A})$; mientras que en el caso de aquellas directamente apoyadas sobre la pavimentación de la fábrica -ánforas del denominado 'livello 1' (Bernal et al. 2014a: 223)-, la concentración de restos era mucho mayor, al haberse conservado protegida por la boca y no haber percolado por gravedad al no existir estanqueidad entre las piezas, como en los envases de la fila media y superior. Precisamente en este último caso, la conservación de los restos es mucho mayor, habiéndose cuantificado el sedimento "bajo la boca' en gramos, y aislado tras el estudio los restos arqueoictiológicos, como ilustra el caso del ánfora siciliana A 64 (Figuras 4 B y C) con 259 gr de tierra, de los cuales 97 son de restos osteológicos de peces.

Indicar, asimismo, que toda esta dinámica de asociación de peces a ánforas de la familia de las Dr. 21-22 se amplía a las formas del tipo Botte 3, como ilustra el hallazgo de restos de escamas, craneales y vertebrales del ánfora A67, de producción campana (Bernal et al. 2014a: fig. 4, A67).

Aparte del interés de estos hallazgos de la pila de ánforas de la Tienda del Garum, que confirman el contenido íctico de las ánforas de los tres tipos asociados a la familia de las Dr. 21/22, debemos tener presente la asociación de estos contenidos a inscripciones pintadas en el 75\% de los casos (seis de los ocho tipos de inscripciones pintadas asociadas 

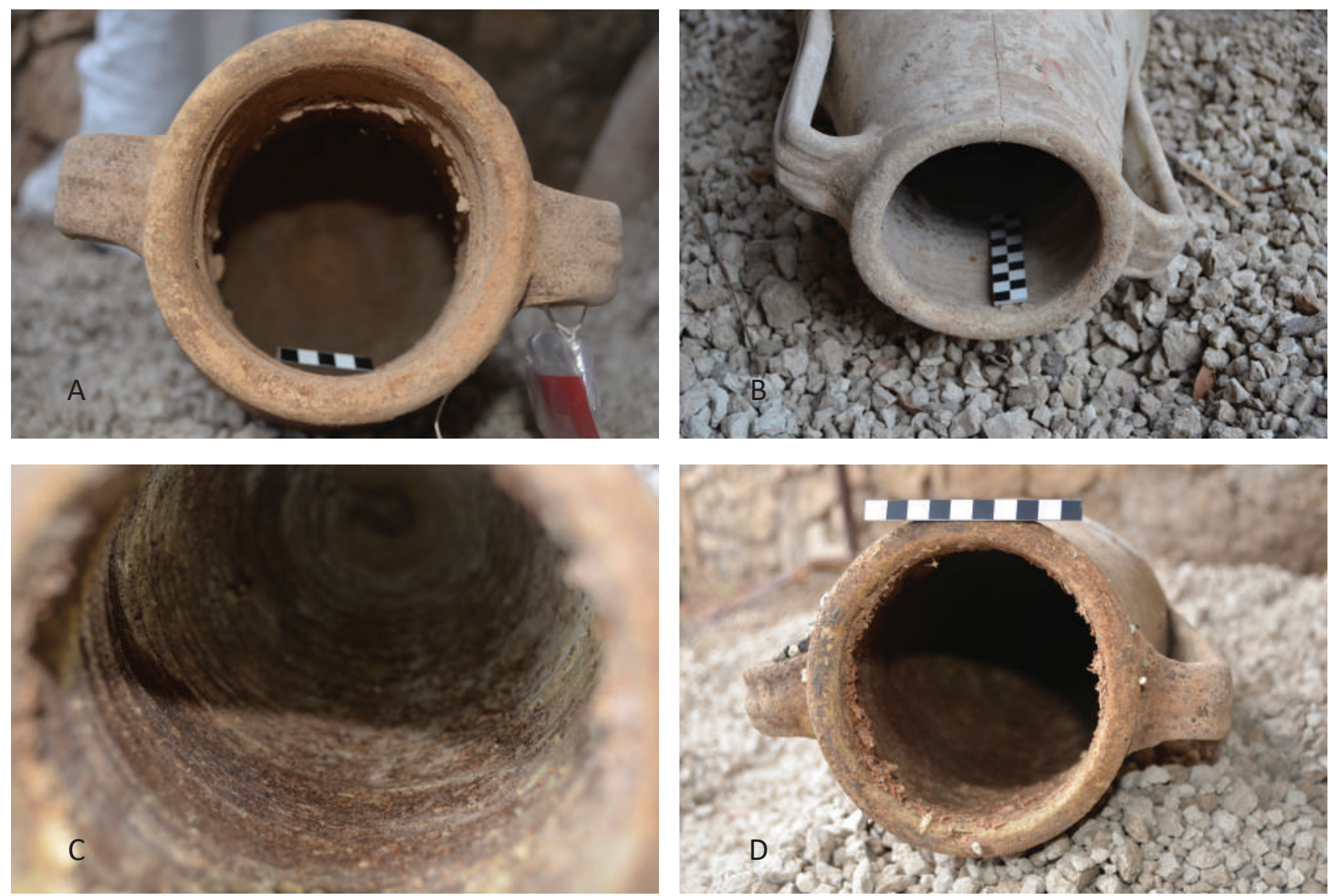

Figura 3. Tipos de CONTEXTOS ICTIO-FAUnísticos ASOCIAdOS A lAS DR. 21-22 CON TITULUS SP DE LA 'PILA D’ANFORE’ DE LA Tienda del Garum de Pompeya (I, 12, 8, CAMPAÑa 2012): escamas (A.- Ánfora A63); escamas y ReStos CRANEALES (B.A29); Y ESCAMAS, VÉRTEBRAS Y RESTOS CRANEALES (A72), CON DETALLE INTERIOR DE LA RESINA (A72).

a estos tipos; Bernal et al. 2014a: 229, fig. 7): caso de CE (A64), COP (A51, 54, 59, 66, 81), COP AB (A79), MAL (A30, $33,35,44,49,62,82,85)$, SP (A18, 57, 63, 68, 71, 72, 73, 74) o VR (34). Es decir, el contenido íctico de todos ellos es evidente, mientras que en el de los otros dos productos conocidos $-A B$, Mixst- (Botte 2009c: 138 y 150) no se ha podido confirmar empíricamente.

Además de lo comentado, durante el proyecto se han compilado todos los restos de paleocontenidos en ámbito pompeyano a los cuales hemos tenido acceso, integrando otros restos de la Tienda del Garum procedentes de las excavaciones de A. Maiuri de los años sesenta, concretamente dos ánforas del tipo Dr. 21-22. ${ }^{8}$ La primera de pasta y tipología calabreso-peloritana (Figura $5 \mathrm{~A}$; inv. 43108), que deparó un conjunto de sedimento interior de 36,5 gr., con una presencia mayoritaria de la especie Spicara smaris (chucla), con al menos ocho ejemplares como NMI - a la cual se podrían adscribir todos los demás huesos de Centracanthidae fragmentarios y no determinables por ello-, así como otra especie indeterminada, mayor que la anterior, posiblemente un espárido. De la 'chucla' se han identificado tanto huesos craneales (posttemporale, otolitus urohyale, palatinum, maxilare, praemaxilare, dentale, articulare

${ }^{8}$ Además de ellas tenemos que citar otra ánfora de la serie 7 ( $n^{\circ}$ 43102) y una Dr. 2-4 itálica ( $n^{\circ}$ 43133).
-Figura 5 B-, operculare, hyomandibulare, epi-keratohyale, scapula, supracleithrale) como vertebrales (urostylus, vertebrae praecaudalis, vertebrae caudalis -Figura 5 C-), confirmando que los ejemplares se habían introducido completos (Rodríguez y Marlasca 2011: 23-29). En el caso de la Dr. 21-22 siciliana -tipo 1- (Figura 5 D; inv. 43129), se identificaron también y casi exclusivamente restos de ejemplares de reducidas dimensiones también de chucla - Spicara smaris-, junto a un praemaxillare dextrum de otro taxón no determinado, cuya presencia parece accidental. También en esta ocasión se ha detectado la presencia de elementos del neurocranium, frontale, posttemporale, quadratum, dentale, articulare -Figura $5 \mathrm{E}-$, operculare, suboperculare, epi-keratohyale y scapula, además de numerosas vertebrae -Figura 5 F- (Rodríguez y Marlasca 2011:29-33).

Por último, hay que unir a este ejemplar otra Dr. 21-22 conservada en el Antiquarium de Boscoreale (Figura 6 a), pero procedente de la Tienda del Garum (Stefani y Borgongino 2005: 87, con citas precedentes), rellena casi exclusivamente de Centracanthidae de nuevo -múltiples vértebras (Figura 6 b) además de restos de viscerocranium y dentale de Spicara smaris (Figura 6 c) y de Spicara maenaa los cuales se suman algunos ejemplares de huesos craneales (viscerocranium y praemaxilare -Figura $6 \mathrm{~d}-$ ) y 

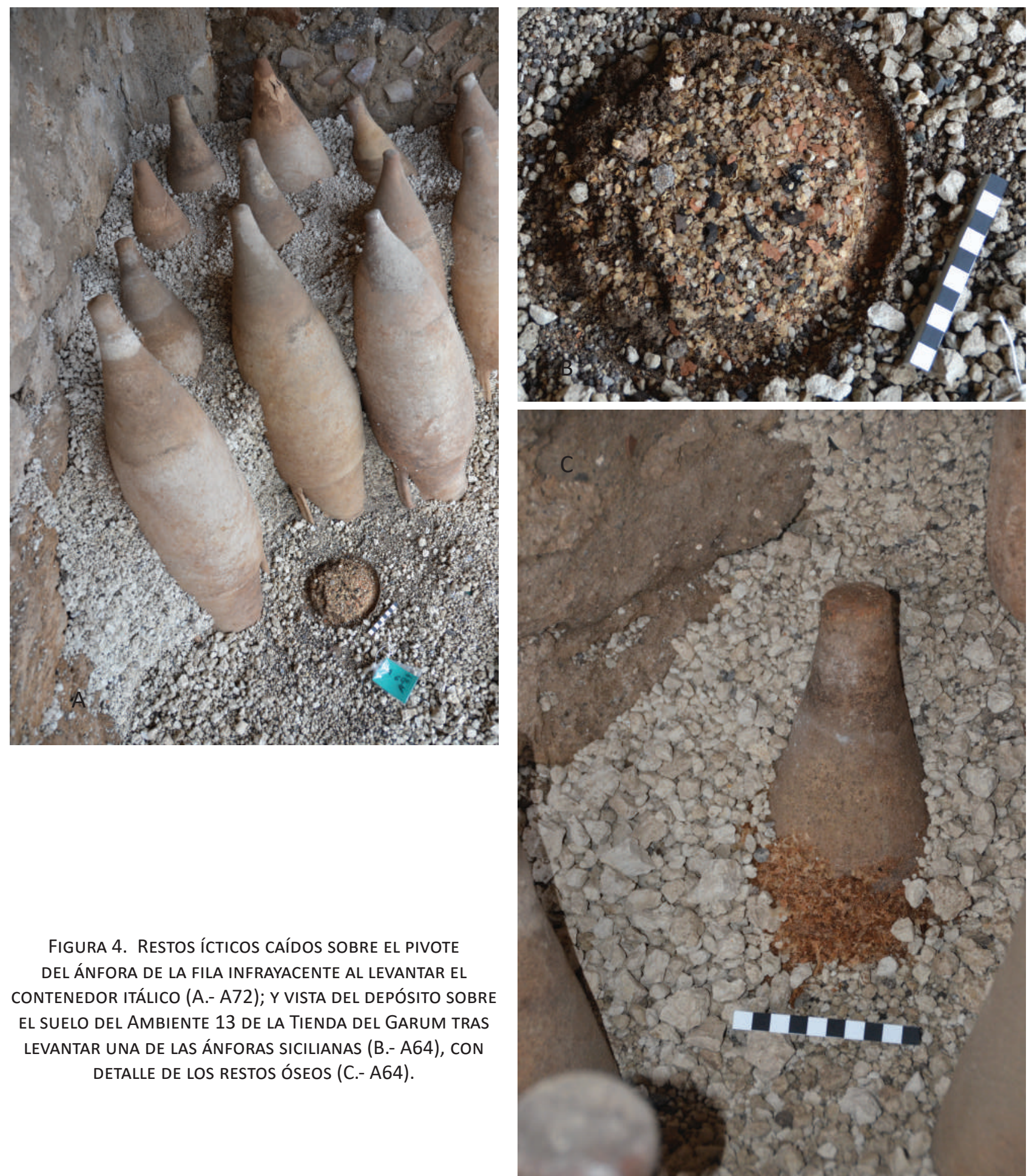

Figura 4. RESTOS Í́cticos CAÍdOS SOBRE EL PIVOTE DEL ÁNFORA DE LA FILA INFRAYACENTE AL LEVANTAR EL CONTENEDOR ITÁLICO (A.- A72); Y VISTA DEL DEPÓSITO SOBRE EL SUELO DEL AMBIENTE 13 DE LA TIENDA DEL GARUM TRAS LEVANTAR UNA DE LAS ÁNFORAS SICILIANAS (B.- A64), CON DETALLE DE LOS RESTOS ÓSEOS (C.- A64).

vertebrales de Boops boops (Marlasca y Rodríguez Santana 2009: 218-221, figs. 11 - 13). De nuevo peces de mediano tamaño en salazón incluidos en estas ánforas suritálicas.

Actualmente toda esta documentación está siendo procesada por los arqueozoólogos (C.G. Rodríguez Santana y R. Marlasca) y por los arqueólogos (los firmantes además de E. García Vargas) a efectos de su interpretación general, habiéndose entregado los informes de las actividades arqueológicas (Bernal y Cottica coord. 2012). Lo que parece quedar fuera de toda duda, como hemos ilustrado en este apartado, es que las Dr. 21-22 descubiertas en la Tienda del Garum de Pompeya, las cuales no presentan evidencias de reutilización (Bernal 2014a: 230, nota 12), es que las mismas estaban destinadas al envasado y comercialización de pescado, habiendo sido vaciadas en estas dependencias artesanales de la ciudad, cuyo producto ha sido hallado sobre los pavimentos de las zonas de trabajo, confirmando su empleo para la elaboración de conservas marinas pompeyanas.

Este hallazgo es de gran interés por su singularidad, al tiempo que permite poner sobre la mesa datos empíricos de notable importancia, algunos de los cuales permiten 

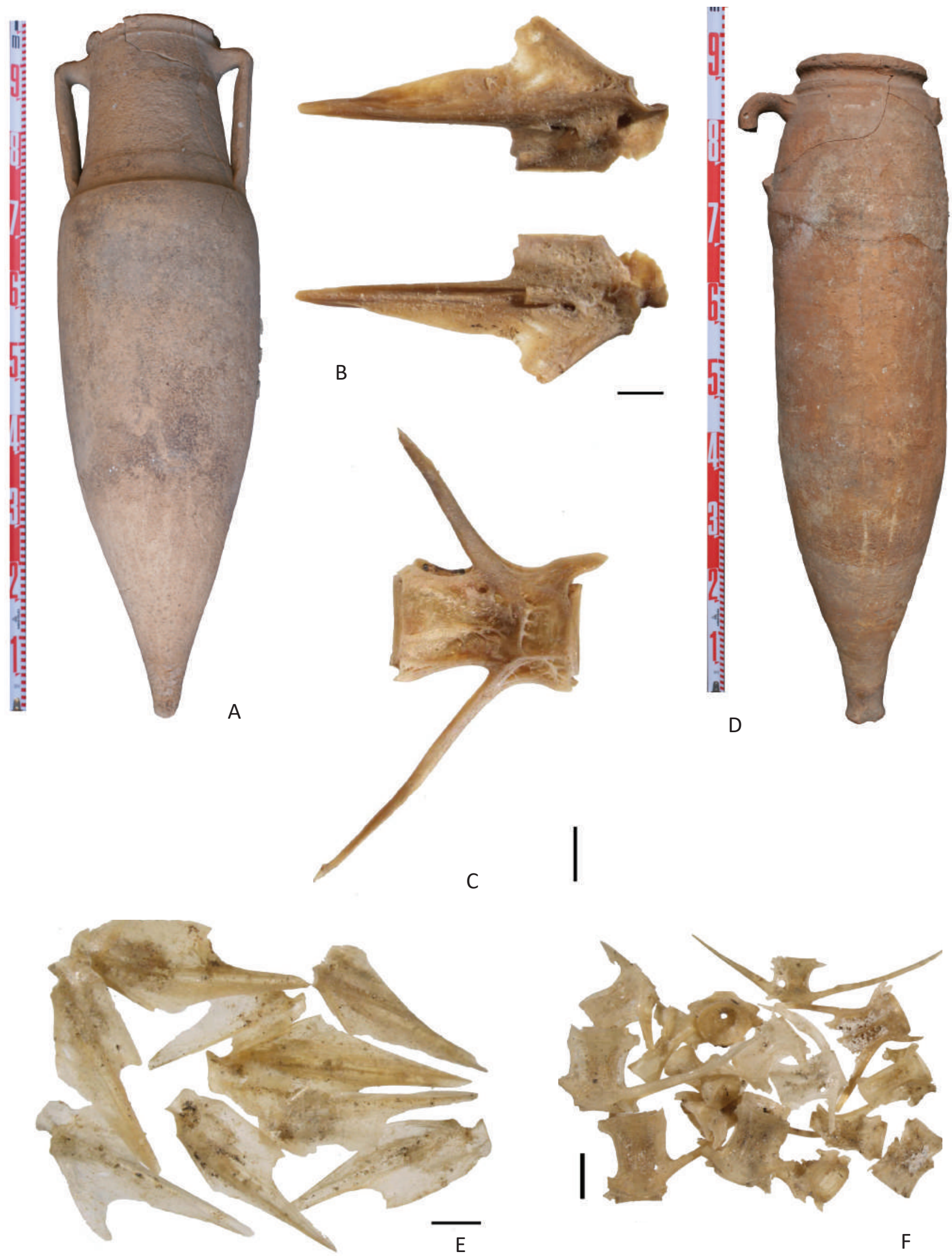

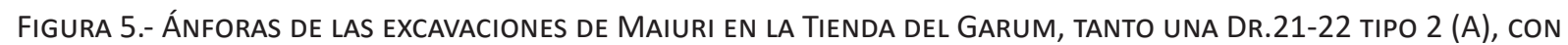
RESTOS DE LA ESPECIE SPICARA SMARIS EN SU INTERIOR -ARTICULARE SINISTRUM (B) Y VERTEBRA CAUDALIS (C) -; JUNTO A OTRO EJEMPLAR SICILIANO DEL TIPO 1 (D), CON EVIDENCIAS DE LA MISMA ESPECIE -ARTICULARIA (E) Y VERTEBRAE (F)-, SEGÚN ROdRÍGUEZ Y MARLASCA (2011, FIGS. M8.- 6 Y 11; Y M9.- 11 Y 15 RESPECTIVAMENTE). 

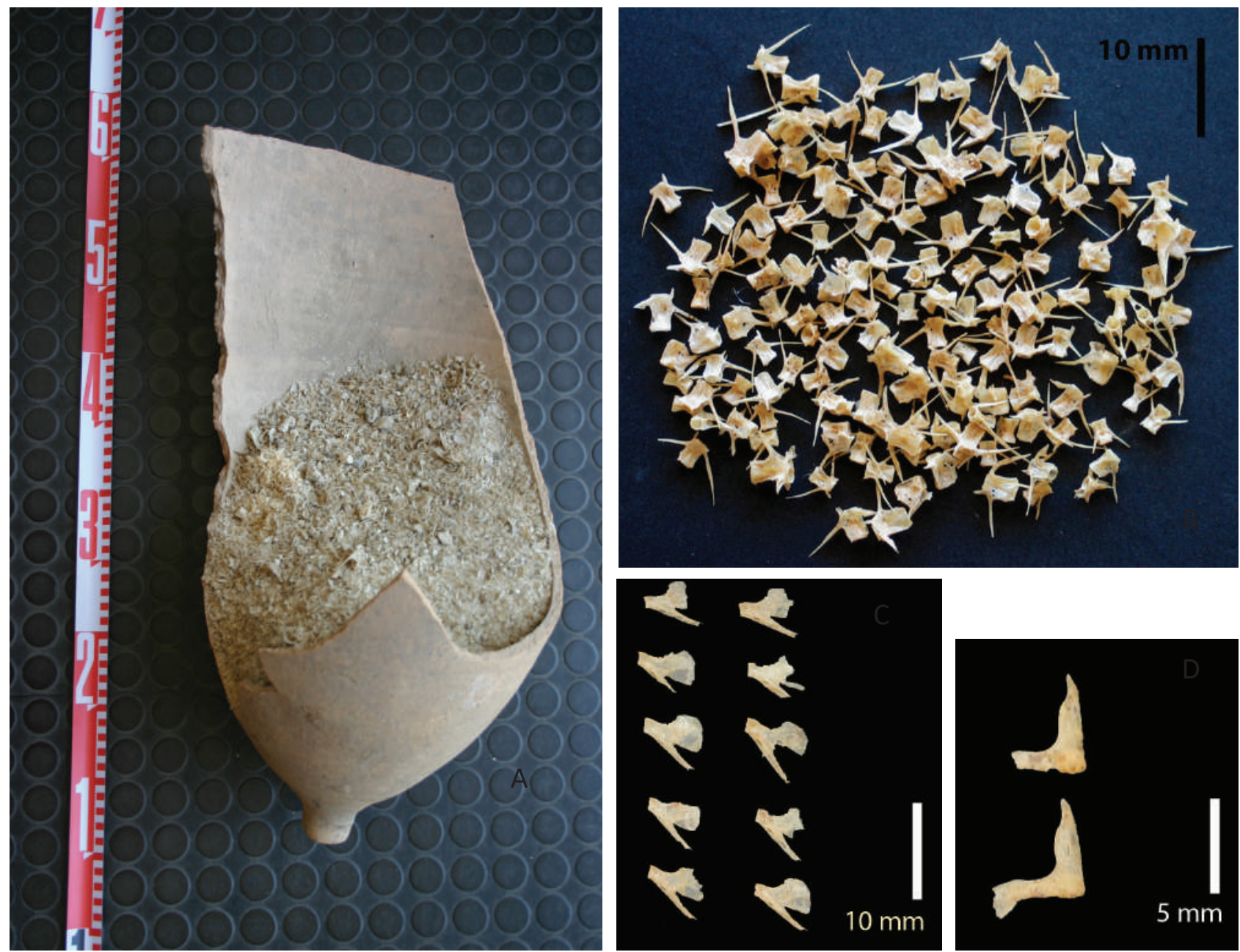

Figura 6. MitAd INFERIOR DE UNA DR. 21-22 conservada en El ANTIQUARIUM De Boscoreale (A), CON UNA QUINTA PARTE DE LOS RESTOS DE PESCADO EN SU INTERIOR, INCLUYENDO MULTITUD DE VERTEBRAE DE CENTRACANTHIDAE (B), JUNTO A DENTALE SINISTRA DE SPICARE SMARIS (C), Y A DENTALE DEXTRA DE BOOPS BOOPS (D), SEGÚN R. MARLASCA Y C.G. RODRÍGUEZ (2011: 218-221, FIGS. 11, 12 Y 13).

matizar propuestas precedentes, como sucede con la complejidad actual de seguir considerando la lectura de CE/CET como cetus o peces de grandes dimensiones -quizás atunes según las interpretaciones de Botte-, ya que los restos óseos aparecidos en las ánforas con este titulus pictus -como los Centracanthidae del ánfora A64 (Bernal et al. 2014a: 229, fig. 7)- son peces de pequeña o mediana talla. Asimismo, ponen sobre la mesa otras temáticas de gran interés, como la complejidad de los preparados piscícolas pompeyanos, elaborados -al menos en el momento de la erupción pliniana- con engraúlidos, espáridos y otras especies pequeñas procedentes mayoritariamente de centenares de millas náuticas de Pompeya, básicamente del extremo meridional de Italia y de Sicilia.

7.5. Dr. 21-22 producidas en Hispania. ¿Modelos elaborados por itálicos emigrados al sur de la península ibérica? Propuestas, talleres y problemática

M. Beltrán, incluyó, en su pionero estudio sobre Las ánforas romanas en España, varias páginas sobre esta forma
(Beltrán 1970: 510-514), ilustrándola con ejemplares hispanos, concretamente con una pieza de Zaragoza y con otra del Tossal de Manises, junto al conocido ejemplo de la esquematización pompeyana del tipo (Figura 7A), aunque a dicha forma le atribuyó posiblemente un ‘origen italiano' (Beltrán 1970: 514).

Dichos trabajos, y la también temprana publicación de las excavaciones de los niveles republicanos y augusteos en la ensenada de Bolonia (Tarifa, Cádiz) por parte de C. Domergue, que incluía epígrafes en su estudio tan significativos como las 'amphores à lèvre en bourrelet arrondi sous lequel court un listel anguleux' y las 'Dressel 21/22', a las cuales atribuía un origen local en función de los defectos de cocción aparecidos (Domergue 1973: 109, 112-115, pl. XIII), permitieron introducir en la bibliografía la posibilidad de una manufactura hispanorromana para esta familia. De manera intermitente, la considerada como 'l'amphore Dressel 21/22 de Baelo Claudia' (Figura 7 B) ha seguido siendo citada en la bibliografía, planteando su singularidad y su autonomía, como en varias ocasiones ha tenido presente F. Mayet (Etienne y Mayet 2002: 120- 
A

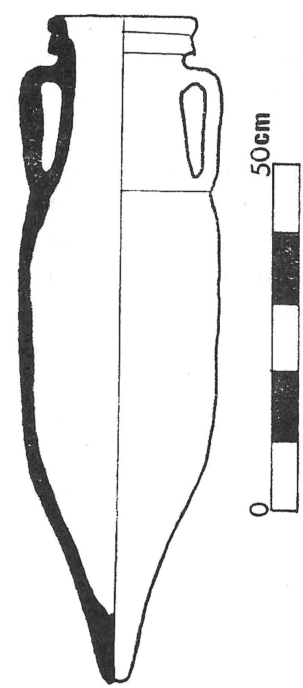

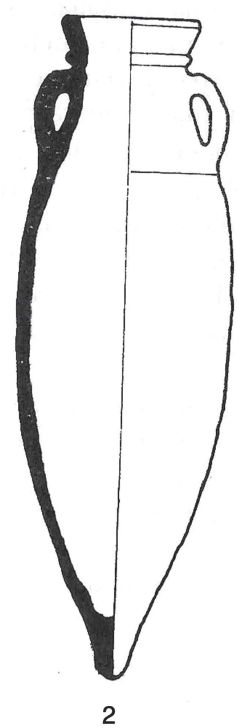

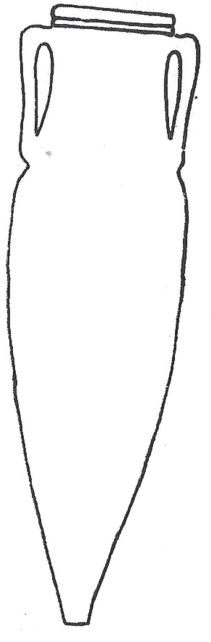

3
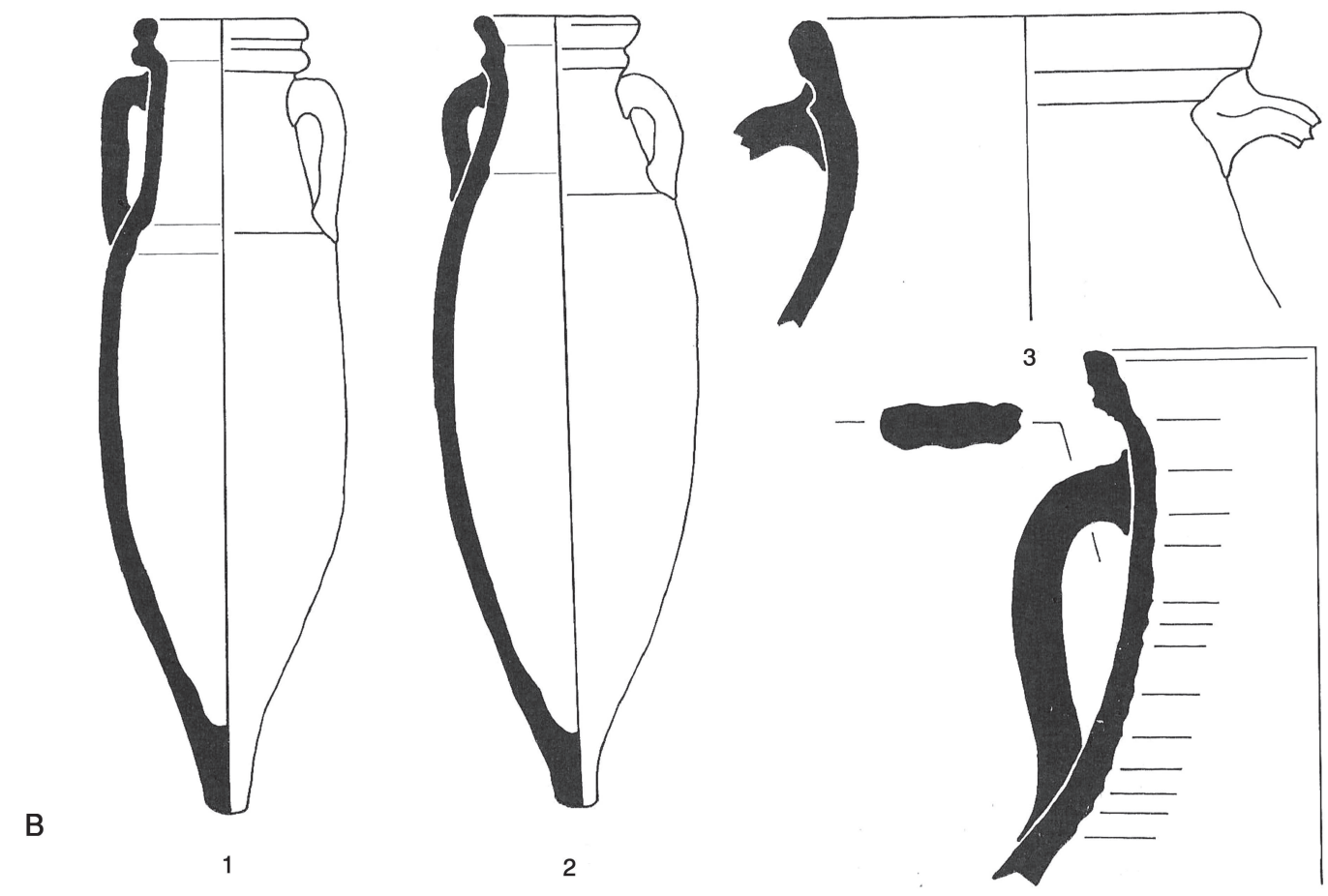

4
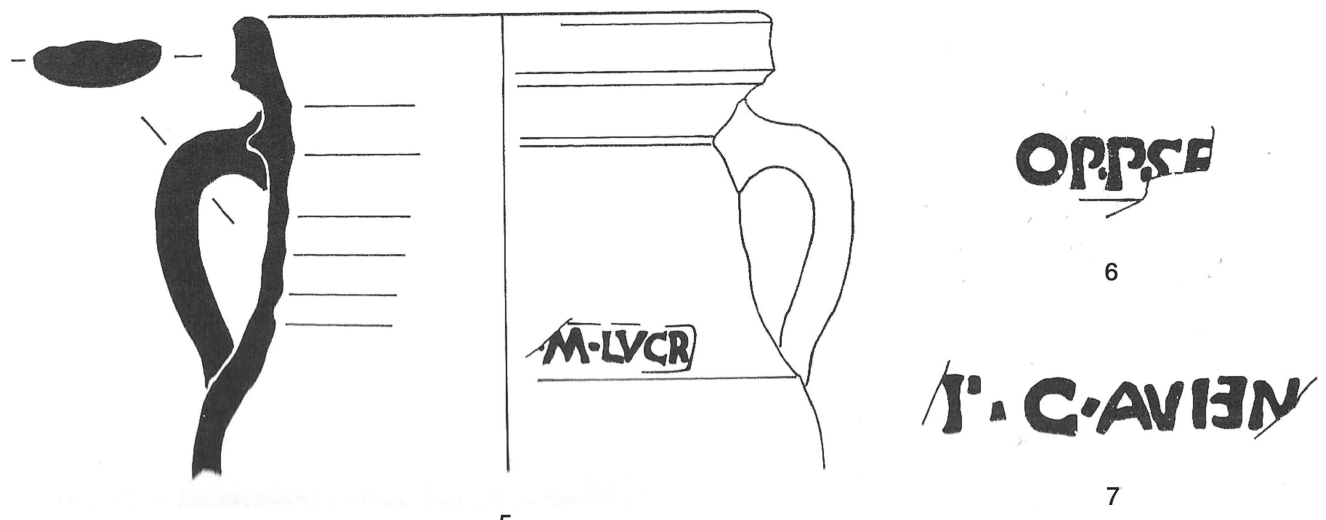

FIgURA 7. ÁNFORAS DR. 21-22 ILUSTRAdAS POR M. BELTRÁN, PROCEDENTES DE ZARAGOZA, TOSSAL DE MANISES Y POMPEYA (A.- 1970, 512, FIG. 205), Y EJEMPLARES DE BAELO CLAUDIA (No 4-7), JUNTO A LOS DOS ANTERIORES -No 1-3-, SEgún F. MAYET (ETIENNE Y MAYET 2002: 121, FIG. 30). 
122). No obstante, nunca ha sido realizado un estudio monográfico de esta forma, lo que ha provocado que haya sido excluida de trabajos como el reciente Catálogo de Ánforas Hispanas (http://amphorae.icac.cat/tipol, ausente en la fecha de consulta -febrero de 2015-) y que incluso algunos autores no la hayan tenido en cuenta a la hora de evaluar la actualización mediterránea de las Dr. 21-22 de Belo, considerando que no se conocía aún perfil completo alguno y que 'l'appellation de l'attribution à la forme 21-22 de Dressel me semblent prématurées' (Botte 2009c: 117, nota 62). Los estudios más recientes siguen citando dichos trabajos antiguos sin novedades (Bezeczky 2013: 124, type 31; Rizzo 2014: 148), en un panorama que es tremendamente confuso en la actualidad.

Evidentemente se trata de un problema complejo y no fácilmente resoluble, por lo que en estas páginas nos limitaremos a dos aspectos: en primer lugar a plantear el status quaestionis de la problemática de esta forma, y en segundo término a presentar algunas evidencias reinterpretadas para tratar de ayudar a la comprensión de este tipo.

\section{Las Dr. 21/22 de la Ulterior/Baetica}

En relación a las Dr. 21/22 de Baelo Claudia-ciudad hispanorromana del conventus Gaditanus, frente a Tingis-, Domergue realizó una síntesis de los diversos tipos de envases documentados en los sondeos en profundidad destinados al conocimiento de la estratigrafía de la ciudad (1973: 109-115). Las Dr. 21-22 aparecían junto a las conocidas Dressel 1 A, Dressel-Lamboglia 1C, Lamboglia 2, 'Dressel-Beltrán 18 I', Dressel 7-11 y las denominadas 'à lèvre en bourrelet arrondi sous lequel court un listel anguleux', y que hoy conocemos como ovoides del valle del Guadalquivir, en proceso de redefinición actualmente (García Vargas, Almeida y González 2011), entre las cuales se incluyen las conocidas hasta hace poco tiempo como Lomba do Canho 67/Sala 1 (=cfr. la ficha de la Ovoide 1 en amphorae.icac.cat). De todos ellos, los tipos más abundantes en los niveles antiguos de la secuencia son la Dressel 1C y las Dr. 21-22, destacando ambas formas por: gran representatividad porcentual (NMI 50 frente a las 30 Dr. 1C, datos relevantes debido a la exigüidad de la superficie de los sondeos realizados); contemporaneidad entre ambas formas; frecuente epigrafía anfórica (en casos coincidente) y, además, similitudes técnicas en las pastas (Domergue 1973: 111 y 114).

Por su parte, las Dr. $1 \mathrm{C}$ de Belo se han datado entre la segunda mitad del s. I a.C. y época augustea, y presentan en cartela rectangular las marcas OP.L. CAE [...], OP.M.LV [...], S.C.G. y S.C.G. en asociación en el mismo labio con los sellos OP.M.LVCR, OP, M. LV[...], OP.L.CAES [...], OP.L.C. [..] y [...]T; además de M. LVCRE sobre el cuello de un ejemplar (Domergue 1973: 112). En relación a las Dr. 21-22 documentadas en Belo, se repiten dos marcas ya documentadas en las Dr. 1C: S.C.G. (no 552, S. 22 II $h n^{\circ}$ 1904, S. 31 IV) y [op.] M. LVCR (no 1903, S. 31 IV) o [o]p M.
LV [cr] (no 2156, S. 36 IV) - posiblemente los no 1903 y 1904 sean el mismo individuo-, y OP.C. AVIENI (no 1813, 1814, 1817 , S. 29 Va) y OP [...] (no 1803, S. 29 Va).

Se trata de producciones fáciles de reconocer por la pasta (dura, color rojo ladrillo, sonora, con fractura irregular, desgrasantes negros y blancos cuarcíticos -con cuarzo eólico- y con engobe beige exterior; a veces color grisnegro al exterior, resultado de la sobre-cocción), detalles macroscópicos que comparten con las Dr. 1C (Domergue 1973: 113 , nota 82 bis).

Todas las características anteriormente citadas de las Dr. 1C y 21/22 (abundancia en los estratos de los siglos I a.C. y I d.c. y singularidad de las pastas), unidas al hallazgo de tres defectos de cocción de piezas sobrecocidas - $\mathrm{n}^{\mathrm{o}}$ 1786-87 (Sondeo 29, couche IV) asociados al tipo Dr. 1C; y no 1998 (S. 32, c. IV) y 2132 (S. 36, c. IV), ambos del tipo Dr. 21-22 (Figura 8), llevaron a este investigador a proponer la manufactura de ambos tipos anfóricos en la ensenada de Bolonia (Domergue 1973: 114). Se trata de fragmentos hipercocidos pero no inutilizados, siendo muy probable su manufactura local, aunque no totalmente confirmada ya que podríamos estar ante defectos comercializables.

Respecto a la tipología de estas ánforas, hay dos factores que han dificultado notablemente su reconocimiento. El primero el elevado estado fragmentario del material (normalmente bordes, fragmentos de cuellos y pivotes no conexionados), y el segundo el escaso detalle de los dibujos: basta comparar la fotografía de la Dr. 21-22 de mayores dimensiones aparecida, documentada en el Sondeo 31 -nº 1903- (Figura 8 b) con el dibujo de la pieza (Figura $10 \mathrm{D}$ ), el cual ha sido incluso reproducido con posterioridad al ser el único existente, sensiblemente retocado (Etienne y Mayet 2002: 121, fig. 30, 5).

En las figuras 9 y 10 presentamos las Dr. 21-22 de los sondeos estratigráficos realizados en Baelo Claudia en los años sesenta, ordenadas por contextos republicanos y altoimperiales. Las ánforas en cuestión cumplen las principales características de este tipo, caracterizándose por la presencia de amplias bocas (19-23 cm de diámetro), la existencia de una carena exterior a la altura del punto superior de adherencia de las asas, cortas asas planas, alargadas y marcadas al exterior por tres acanaladuras, resultado de digitaciones del alfarero. Durante las excavaciones ya se advirtió la notable diversidad de bordes que presentaban estas ánforas, siendo los más característicos (Domergue 1973: 112):

- De perfil triangular con acusada moldura en la zona superior de la inserción del asa (nº 1903).

- Perfil triangular, pero sin moldura ( $n^{\circ}$ 1966), siendo frecuente que se ubique una acanaladura al exterior, dividiéndolo en dos partes ( $n^{\circ} 759,973$, 2129).

- Borde redondeado, conservando la moldura ( $n^{\circ}$ 1089, 1799). 

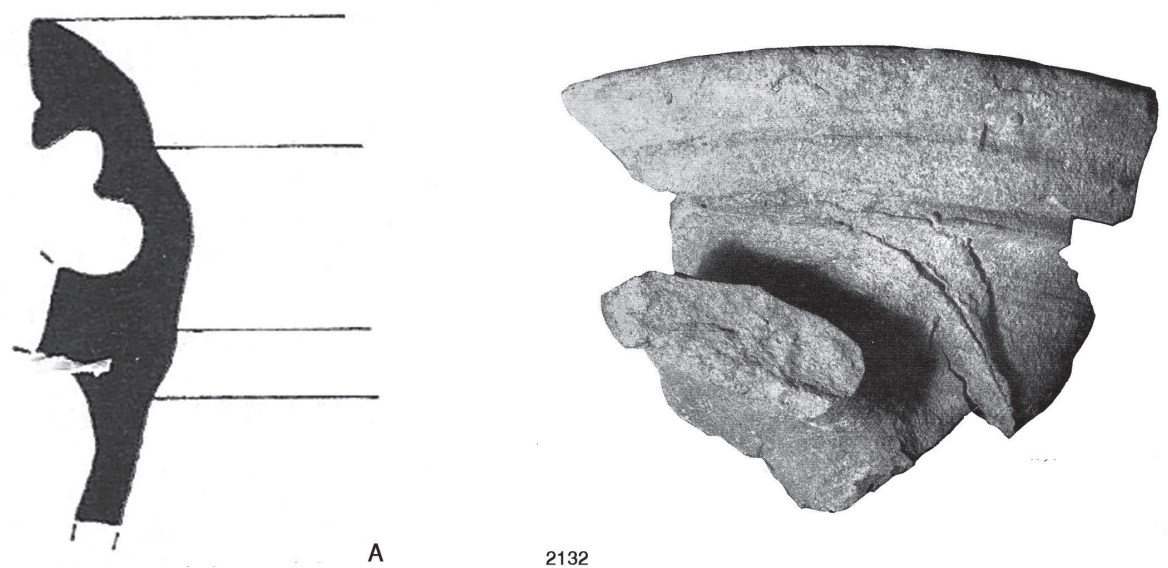

A

2132

Figura 8. Dibujo Y Fotografía del DEFECTO DE COCCIón de DR. 21-22 PROCEDENTE DE BAELO

Claudia (A.- Domergue 1973: PL. XIII, №

2132) Y DETALLE DE UNO DE LOS FRAGMENTOS DE MAYORES DIMENSIONES ASOCIADO A ESTE TIPO (B.- № 1903, S-31, C. IV).

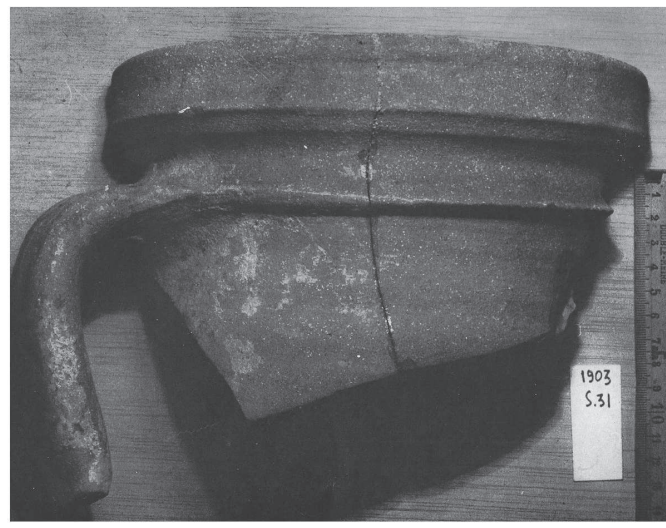

Se han relacionado estas Dr. 21-22 de Baelo Claudia con las denominadas 'amphores à saumure d'Espagne' (Etienne y Mayet 2002: 122, nota 69), siendo cierto que algunas de ellas, como los ejemplos del pecio Titan, y de sendos ejemplares aislados de Marsella y del Golfo de Fos (Chapelle Notre-Dame-de-la-Mer) son similares respecto a la morfología de la forma, aspectos sobre los cuales habrá que profundizar en el futuro.

Por último, es importante aclarar la cuestión cronológica. Domergue planteó para esta forma una cronología centrada 'à Belo, cette forme caractérise exclusivement le $\mathrm{I}^{\mathrm{er}}$ s. av. J.C. et l'époque augustéenne' (1973: 113). A pesar de ello se comenta explícitamente la presencia de un fragmento de esta tipología en niveles de finales del s. II/primera mitad s. I a.C. (nº 1089, S. 40, VI), siendo especialmente abundantes en estratos pre-augusteos ( $\mathrm{n}^{\circ}$ 966-973, S. 40 V; 1797-1803, 1809-1814, 1817-1819, S. 29 Va) y augusteos (no 759-760, S. 26 V; 1740-1741, S. 29 IV; 1996, 1998, S. 32 IV; 2127-2129, 2131-2132, 2158-2160, S. 36 IV), planteando estos investigadores que los hallazgos posteriores deben ser considerados como residuales.

En segundo término, recordar que además de lo comentado existe un importante taller alfarero en la Bahía de Algeciras que también fabricó ánforas del tipo Dr. 1C y afines a las Dr. 21/22: se trata de El Rinconcillo, conocido desde las excavaciones de M. Sotomayor a finales de los años sesenta e inicios de los setenta, y en el cual se volvió a intervenir en el año 2002 (Bernal y Jiménez-Camino 2004). Domergue (1973: 112) aisló algunas ánforas aparecidas en Baelo Claudia con marca SCC de todas las demás, considerando que las pastas eran diversas, por lo que podrían tratarse de importaciones de El Rinconcillo, distante unos 50 kms. Entre la producción de El Rinconcillo se encuentran ánforas de amplia boca, tradicionalmente consideradas como afines a las Lomba do Canho 67/Sala I - actualmente denominadas Ovoide 1, como hemos indicado anteriormente- (Bernal y Jiménez Camino 2004: 596 y 597, fig. 11). Estas ánforas, con diámetros de borde cercanos a los $20 \mathrm{~cm}$ de diámetro, se caracterizan además por unas asas de cinta muy desarrolladas (Figura 11a). De nuevo nos encontramos con ejemplares de carácter fragmentario, por lo que no resulta sencillo conocer la morfología general del envase. Es posible que estas producciones se correspondan con Dr. 21-22, como fueron llamadas en su momento por algunos autores (Bernal y Jiménez-Camino 2004: 601; Fernández Cacho 1995, 1997). Lo que sí es importante es recordar que estas formas son sincrónicas a las Dr. 1C que también se fabrican en este alfar campogibraltareño -como atestigua, por ejemplo, la documentación de ambas formas en la U.E. 6 de la intervención del año 2002 (Bernal y Jiménez-Camino 2004: 597)-, y que además 

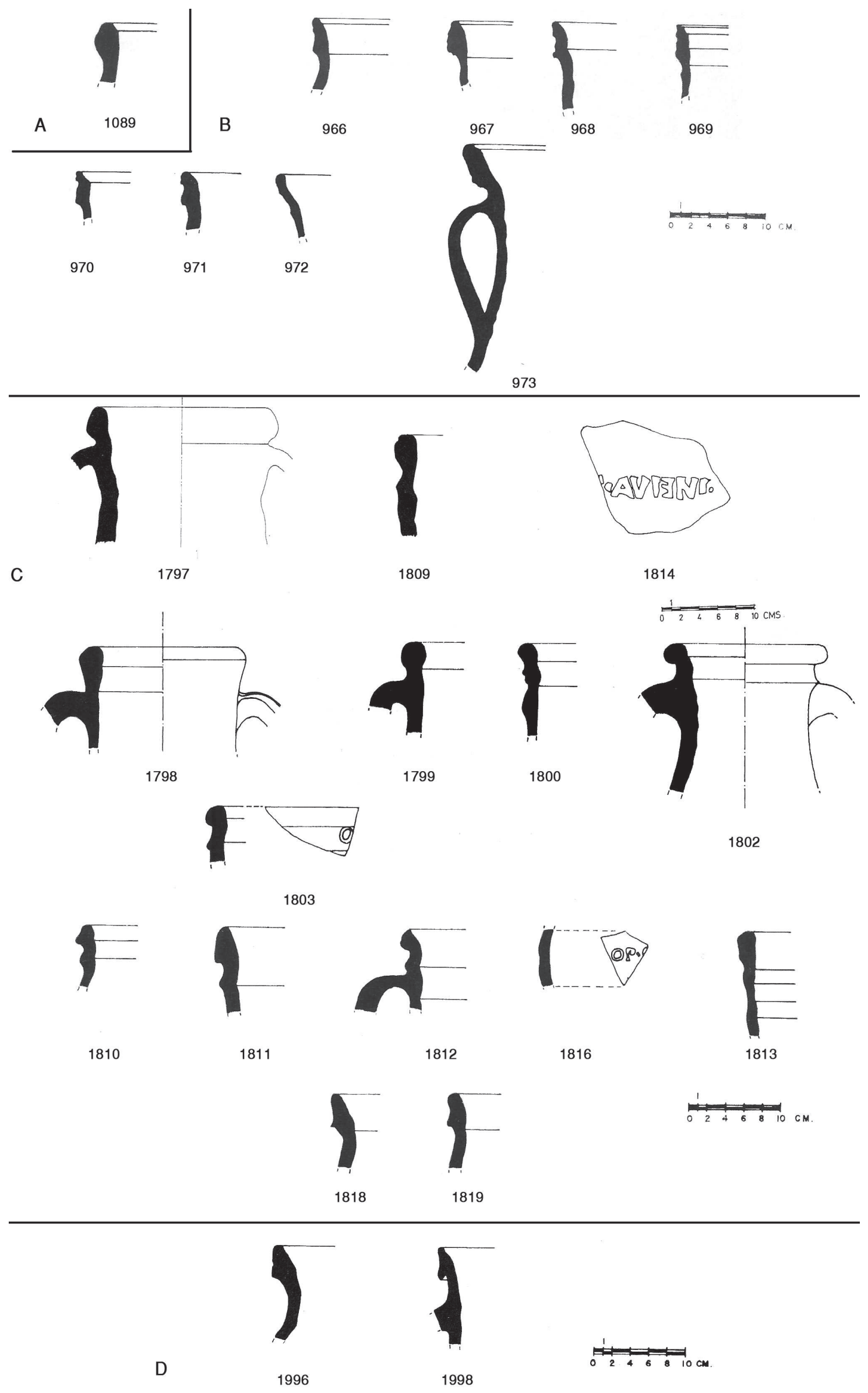

Figura 9. DR. 21-22 de Belo SEgún DOMERgue (1973), ORdenAdAS POR HORIZONTES CRONOLógicos FECHADOS ENTRE EL 125-50 A.C. (A.- № 1089, SONDEO S 40, COUCHE VI) Y ENTRE EL 50-30 A.C. (B.- 966-973, S. 40 c. V; C.- 1797-1800, 1802, 1803, 1809-1814, 1818, 1819, S. 29 C. VA; D.- 1996, 1998, S. 32 C. IV). 


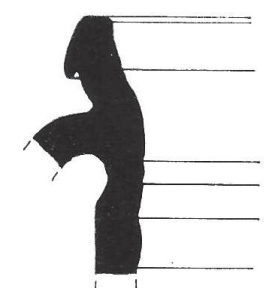

A

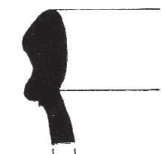

B 2158
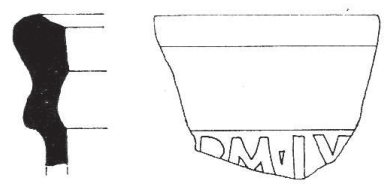

2156

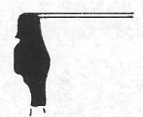

759 760

C

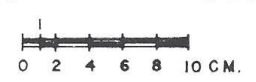

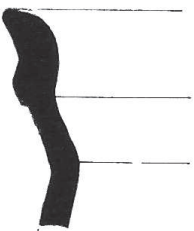

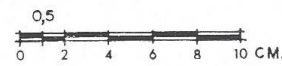

1740

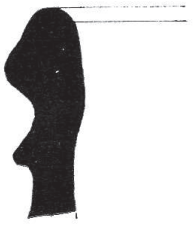

2159
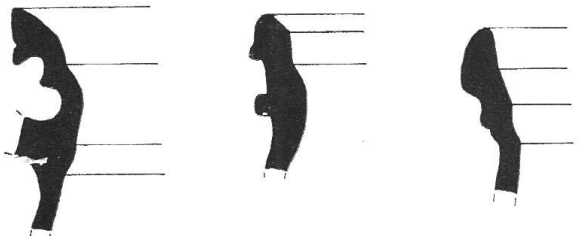

2131

2132

D

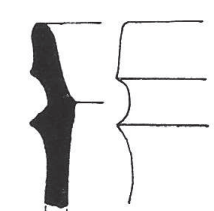

1905

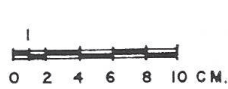

2127
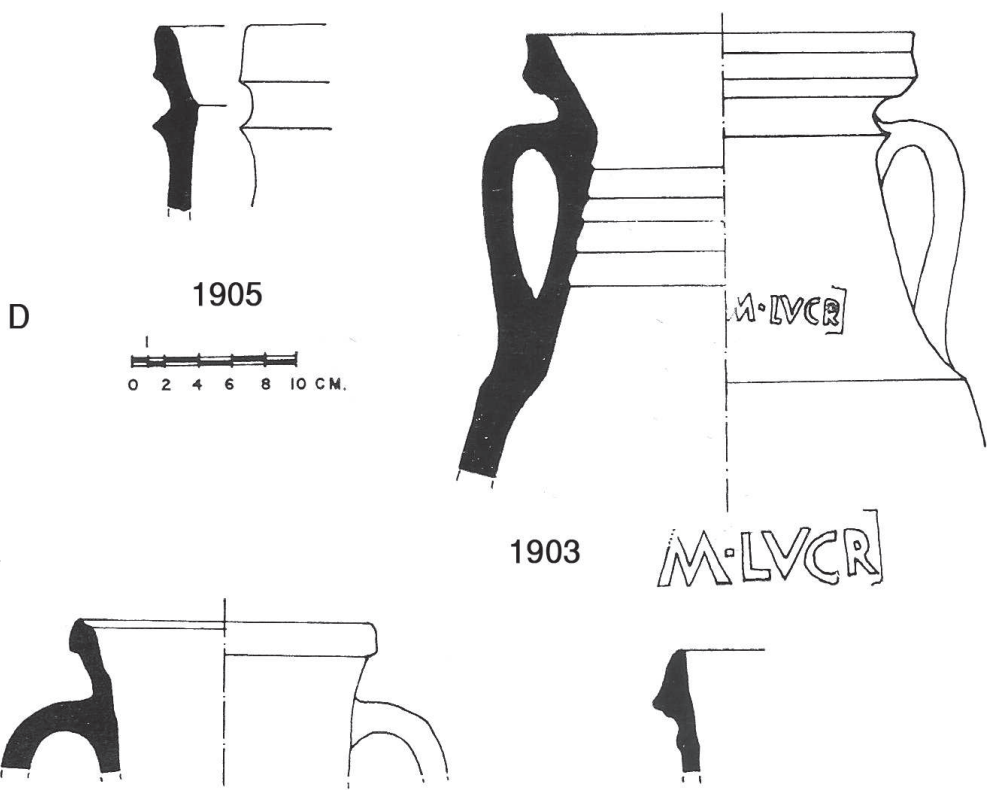

1979
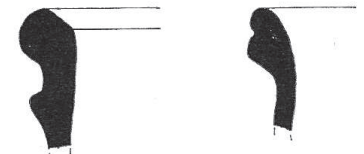

2128

2129
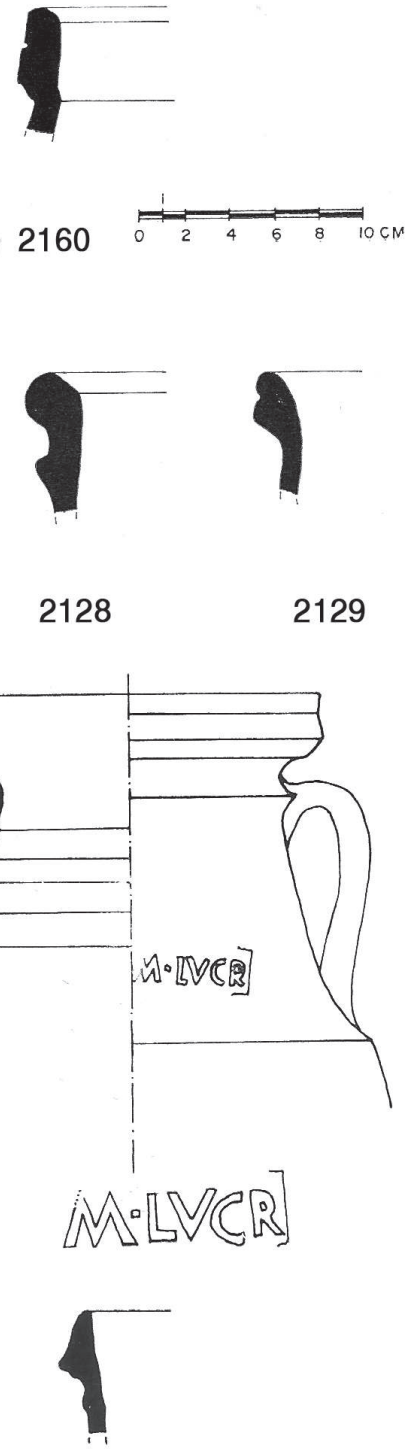

$\mathrm{F}$

612

G

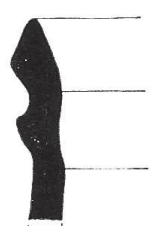

2089
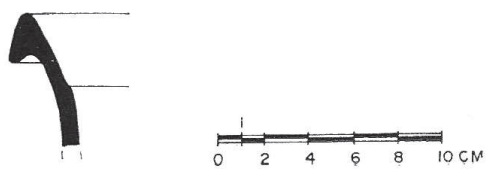

2090

Figura 10. Dr. 21-22 de Belo Según Domergue (1973), feChadAs en ÉPoCa de Augusto (A.- № 1740, 1741, S. 29, C. IV; B.- 2127-2129, 2131, 2132, 2156, 2158-2160, S. 36, C. III), ENTRE AUGusto y CLAUdio (C.- 759, 760, S. 26, C. V), Tiberio-Claudio (D.- 1903, 1905, S. 31, C. IV), Tiberio-Nerón (E.- 1978, 1979, S. 32, C. III), ÉPoca ALtoIMPeRIAL (F.- 612, S. 25, C. III) Y SIGLO IV D.C. (G.- 2089, 2090, S. 36, C. III). 

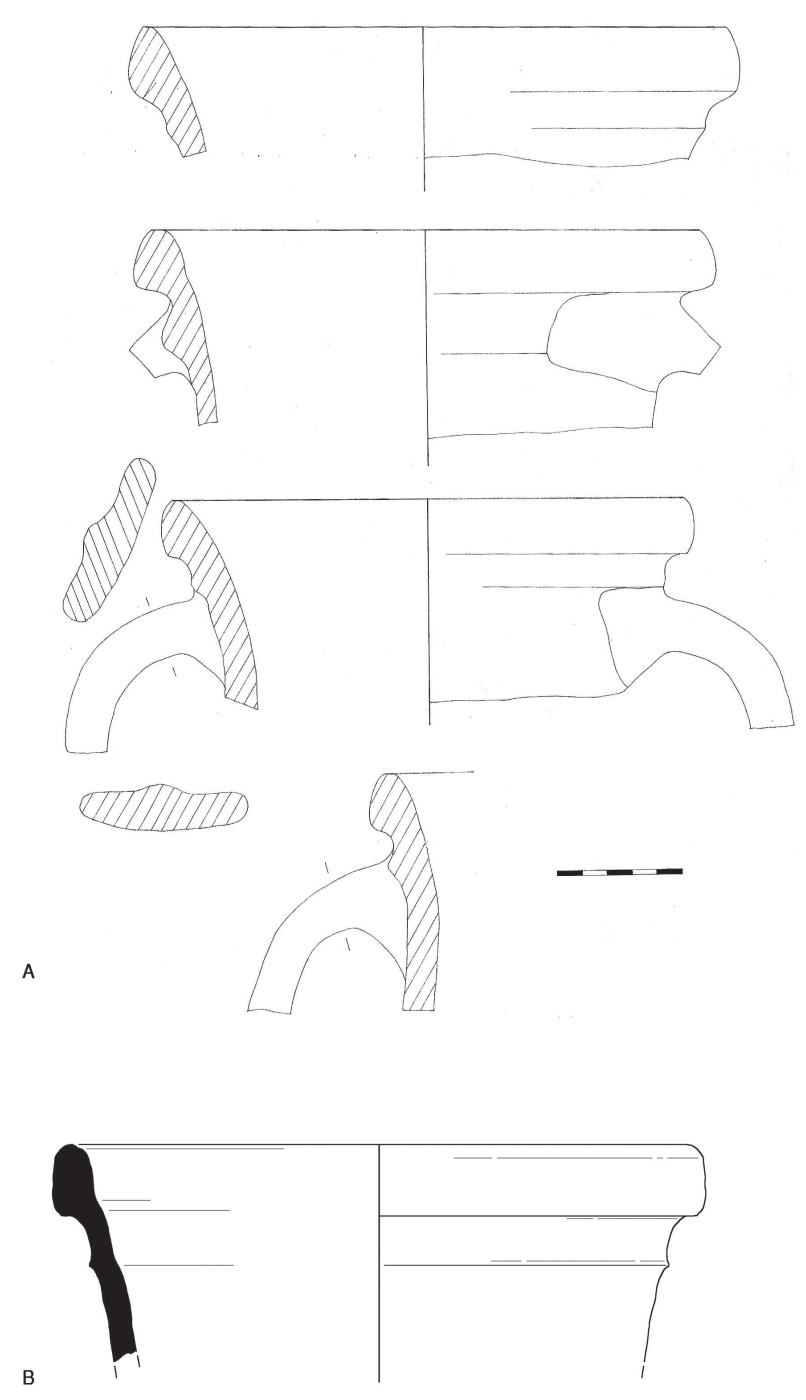

Figura 11. Ánforas del taller de El Rinconcillo en LA BAHÍA DE ALGECIRAS (A), AFINES A LA FAMILIA DE LAS DR. 21-22 (BERNAL Y JIMÉNEZ-CAMINO 2004: 597, FIG. 11), Y EJEMPLAR AUGUSTEO PROCEDENTE DE LAS RECIENTES EXCAVACIONES EN LAS TERMAS MARÍTIMAS DE BAELO CLAUDIA (B.- BERNAL ET AL. 2013: FIG. 13.3).

la producción de la figlina es muy parecida a la citada anteriormente de Baelo Claudia, con marcas similares SCET y S.C.G.-, que hacen de ambos enclaves un unicum en todo el tramo costero hispánico, ya que no se conocen otros alfares con una producción similar (recientemente Díaz Rodríguez 2014). Recordar, asimismo, que en los últimos años se ha propuesto un inicio productivo en esta figlina entre el 100/70 a.C. y una actividad hasta el 30/40 d.C., debiendo relacionarse estas producciones con la primera fase de producción del alfar (problemática y discusión en Bernal y Jiménez-Camino 2004: 600).

Por todo lo comentado, nos parece demostrada la existencia de una producción de ánforas del tipo Dr. 21-22 en la Hispania meridional costera, contando hasta la fecha con al menos dos centros productores bien identificados, tanto en la bahía de Algeciras (El Rinconcillo) como en la costa del estrecho (ensenada de Bolonia), aunque no faltan otras propuestas. ${ }^{9}$ Cronológicamente parece demostrado estratigráficamente que la datación de estas series es anterior a la de las Dr. 21-22 itálicas, como ya se planteó en su momento (Domergue 1973: 113), ya que con total seguridad se fechan entre el 50-30 a.C. en Bolonia, y posiblemente desde algunas décadas antes a tenor de las cronologías de El Rinconcillo y de los estratos basales de Bolonia.

Respecto al contenido de estas 21/22 hispánicas, en los últimos años han aparecido muchos indicadores que parecen confirmar su relación con las conservas piscícolas. Desde el hallazgo de las conocidas grecoitálicas tardíasDr. 1A iniciales regionales con paleocontenido marino en los estratos del barrio meridional de Baelo, interpretadas como contenedores de salsas mixtas del tipo garum (Bernal et al. 2007); pasando por la interpretación de las marcas de estos envases como relacionadas con una posible Societas Cetariorum Gaditanorum (Étienne y Mayet 1994); hasta desembocar en la ubicación costera y litoral de estos talleres, cerca o en el entorno de las fábricas salazoneras, argumentos sólidos al respecto (Bernal, García y Sáez 2013: 364-366). De ahí que sea muy probable que las Dr. 21-22 se incluyan en esta dinámica, siendo la hipótesis de trabajo más viable en el estado actual de la investigación.

Con todo y con eso, queda mucho por trabajar en este sentido en los próximos años, sobre todo en lo referente a la tipología de estos envases, aceptados como claramente como Dr. 21-22 béticas destinadas al envase de salazones según algunos autores (Beltrán 2014: 150-151). Siguen siendo recuperadas formas similares a esta tipología (Figura 11 b), como sucede con una pieza de las Termas Marítimas de Baelo Claudia fechada en época augustea o tardo-augustea (Bernal et al. 2013: U.E. 2218, 131 y 132, fig. 13, 3), similar tipológicamente a algún ejemplar itálico (Botte 2009c: 148, fig. 4-32, CU. 8) y a las ánforas de El Rinconcillo.

En la figura 12 reproducimos un ejemplar completo de Altino que podría corresponderse con una Dr. 21-22 de producción occidental (Toniolo 1991: 30, fig. 22, AL 13898). Efectivamente en el museo de esta localidad noritálica destacan dos ejemplares de los cinco que se ajustan a esta tipología (Toniolo 1991: 153, nº 173177). Considerados como un cadus para la exportación de resina/pix, se conservan dos ejemplares completos, singulares por varios motivos. En primer lugar porque presentan una tipología emparentable con las producciones hispánicas, caracterizada por una amplia boca de $19 \mathrm{~cm}$ de diámetro, con alto cuello en forma de hipérbole, largas asas de trayectoria curvilínea, con acanaladuras dorsales y amplia anchura en la zona de unión superior -detalle artesanal similar al de algunas

\footnotetext{
${ }^{9}$ Recientemente se ha planteado la posibilidad de una producción afín a esta tipología procedente de Malaca, actualmente en fase de estudio (Chacón, Arancibia y Sáez e.p.).
} 


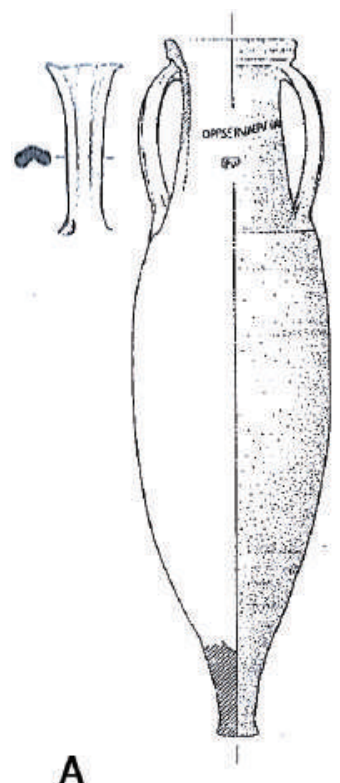

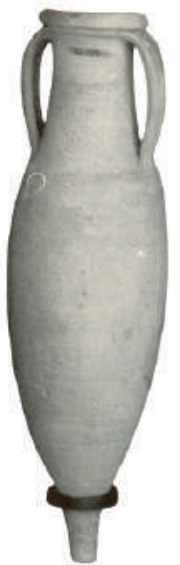

B

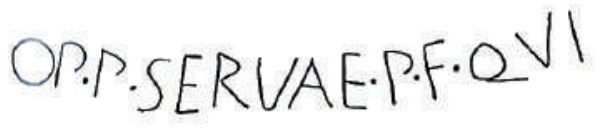

$P \vee \Gamma$

OP. P. SERVAE. P. F QVI/PVP (AL 13898; sp.)

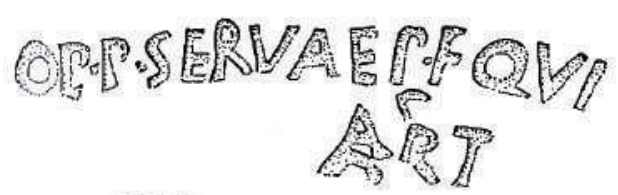

OP. P. SERVAE. P.F.QVI/ART (AL. 13899; sp.)

C

Figura 12. Dibujo (A) y fotografía (B) de unA de las dos Dr. 21-22 completas de Altino (Toniolo 1991: 30 , Fig. 22 Y 157, FIG. 366, № 174 RESPECTIVAMENTE), POSIBLE DR. 21-22 DE PRODUCCIÓN OCCIDENTAL, CON DETALLE DE LAS MARCAS ASOCIADAS A CADA UNA DE ELLAS (C.- TONIOLO 1991: 194).

producciones de El Rinconcillo-, cuerpo fusiforme no muy ancho (entre 28,5 y $30 \mathrm{~cm}$ ) y pivote cilíndrico macizo de base plana, generando un envase con una altura total de $107 \mathrm{~cm}$. Las pastas, aparentemente, son compatibles con las producciones de los talleres gaditanos a tenor de la descripción por la coloración rojiza con desgrasantes blancos (Toniolo 1991: 153). Estas dos piezas, datadas en el s. I d.C. aparentemente, ${ }^{10}$ presentan además, sendas inscripciones in collo muy similares a las comentadas en el caso de Baelo Claudia, concretamente OP.P.SERVAE.P.F. QVI/ART (no inv. ALT 13899, no Catálogo 173) y OP.P.SERVAE.P.F.QUI/PVP (nº inv. ALT 13898, nº Catálogo 174) (Toniolo 1991: 29, 194-195), para las cuales no conocemos paralelos (CEIPAC 10586 y 10587, sin datos adicionales). Estos sellos (Figura 12 c) son muy similares a los comentados anteriormente de Baelo Claudia, por lo que quizás esta pieza altinense pueda proceder de estos talleres y constituir el prototipo de la forma.

\section{Las Dr. 21/22 tarraconenses}

Como se ha visto a lo largo de estas páginas, dos de los envases anfóricos utilizados para la definición del tipo proceden de la costa noreste de la península ibérica, respectivamente de Zaragoza y del Tossal de Manises.

Respecto al ánfora de Caesaraugusta, un reciente trabajo sintetiza el estado de la cuestión (Beltrán 2014). Se trata de una pieza muy singular, al estar completa y presentar el sello IVLI.THEOPHIL in labro y el titulus fragmentario T.LXV in collo (Figura 13A), la cual había sido utilizada

\footnotetext{
${ }^{10}$ Las marcas con la fórmula $O P(v s)$ constituyen un elemento claramente arcaizante, como sucede con las producciones gaditanas aquí comentadas, quizás un indicio de la mayor antigüedad de estas piezas.
}

con más de medio millar de envases de diversa tipología (se han inventariado 849 ejemplares, sobre todo Dr. 7/11, Dr. 12, pero además Dr. 24, Dr. 25, H. 70, Pascual 1, Dr. 1B, Dr. 6, Dr. 2-4, Dr. 5 y Dr. 28) para generar una plataforma seca en una obra de saneamiento urbano entre el curso de los ríos Ebro y Huerva, en la cual estos envases fueron reutilizados en el sistema de drenaje, fechado por la propia tipología de las ánforas y por numerario entre el 10-1 a.C. (Beltrán 2014: 144-145).

Originalmente fue considerada una Dr. 21-22 itálica, pero estudios posteriores y la filiación tarraconense del sello aclararon su manufactura en el noreste peninsular. M. Beltrán ha propuesto la relación de este tipo con el denominado Tarraconense 2 - Fenals 1 (Beltrán 2008: 276-277), caracterizado por material autóctono de la figlina catalana homónima en Lloret de Mar (Tremoleda 2000: 117 y 136, fig. 80), aunque esta propuesta no ha sido aceptada por otros autores (López Mullor y Martín 2008: 694, fig. 2). Lo más significativo a nuestro parecer es el sello de Iulius Theophilus que ostenta el ejemplar, conocido sobre ánforas del tipo Pascual 1 tarraconenses, los cuales se conocen en Cap de Volt, Port-la Nautique, Narbona, Vieille Toulouse y Barcelona, ${ }^{11}$ fechados en época augustea, algunos claramente entre el 30-20 a.C., y que podrían asociarse a algunos de los talleres alfareros catalanes como el de San Boi de Llobregat, por criterios arqueométricos (síntesis en Beltrán 2014: 147-148). Respecto al contenido de estas Dr. 21-22 tarraconenses,

\footnotetext{
${ }^{11}$ En la Base de Datos epigráfica CEIPAC, de la Universidad de Barcelona, se incluyen 29 marcas como esta asociadas a las Pascual 1, además del ejemplar zaragozano (CEIPAC 26566), procedentes de Port-la-Nautique (21 ejemplares) y de Malard-Narbona (2), Narbona (1), Neuss (1), Vieille Toulouse (1), Cap del Vol (1), Barcelona (1) y Saint-Romain en-Gal (1); y un ejemplar en Dr. 2-4 tarraconense de la Alcudia-Elche (CEIPAC 23937).
} 


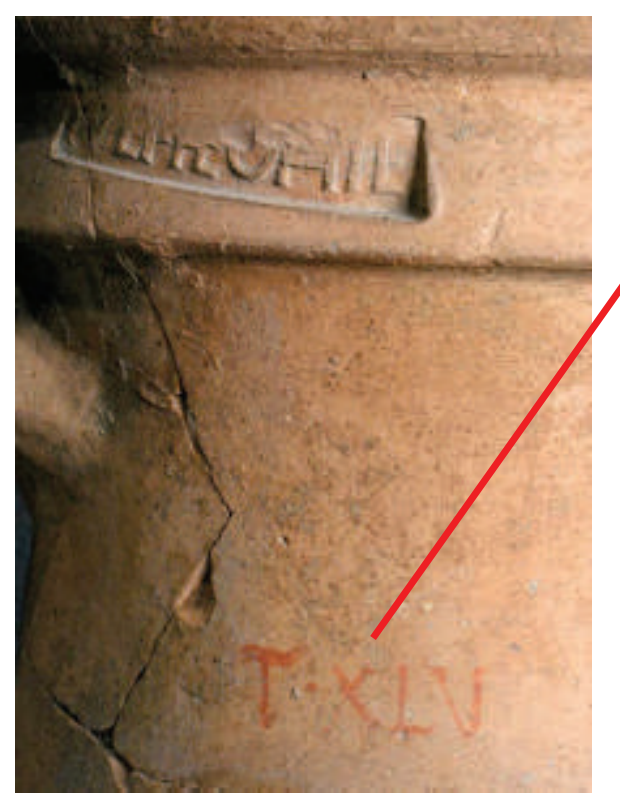

FIGURA 13. DR. 21-22 DE IULIUS THEOPHILUS PROCEDENTE DE ZARAGOZA (A.- SEGÚN BELTRÁN 2014: 147, FIG. 1 Y 2), Y COMPARACIÓN CON LA DR. 21-22 CON SELLO CEIONI MAXIMI DE POMPEYA (B).

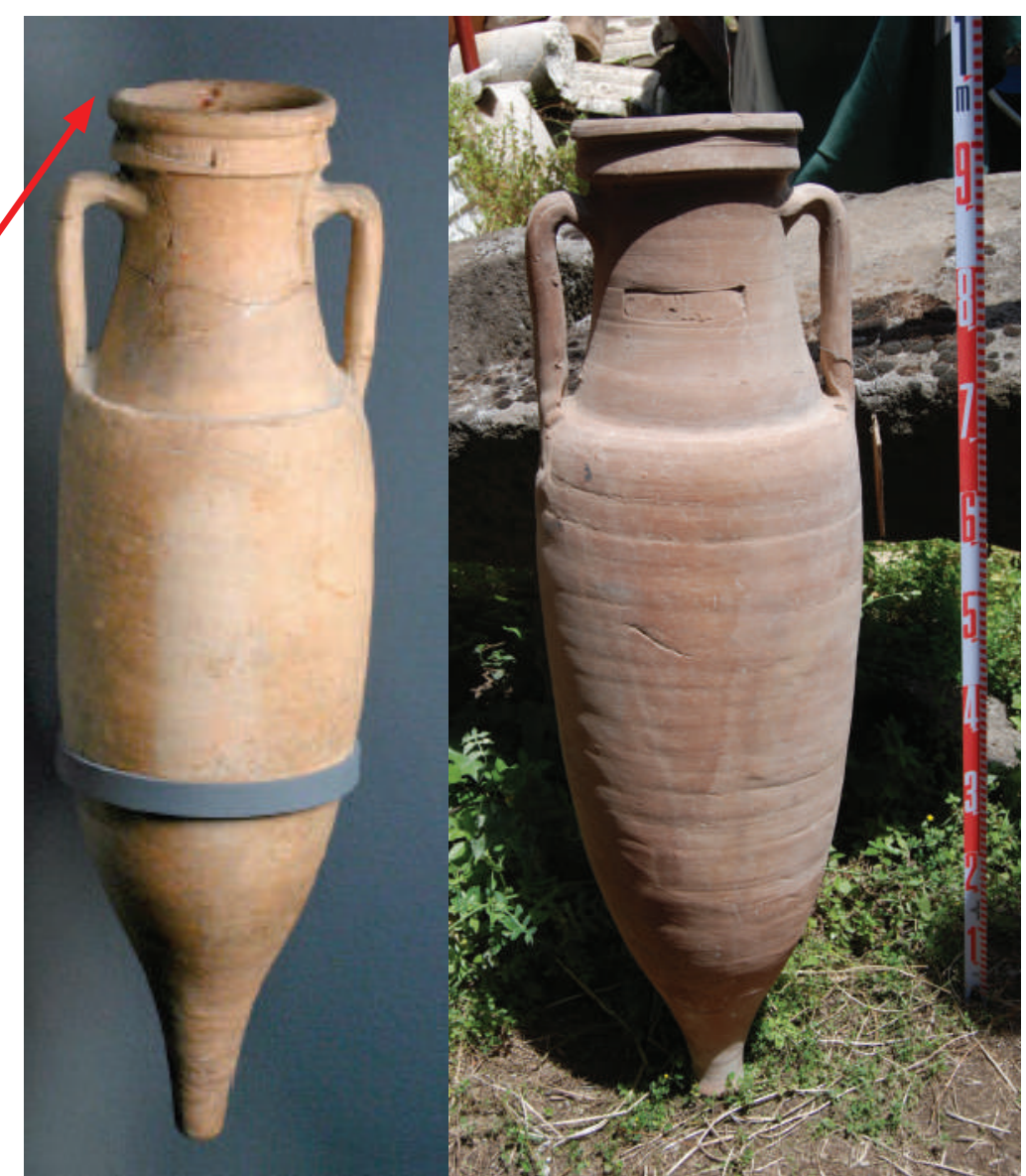

se propuso originalmente vino (Beltrán 2008) y más recientemente salazones piscícolas por analogía formal con las ánforas del tipo 3 de Botte, incluyendo la amplia anchura de su boca (Beltrán 2014: 152-153), aunque no existe constatación empírica de dicha hipótesis.

Por nuestra parte, pensamos que las analogías del ánfora de Zaragoza (única completa conocida hasta la fecha) son muy notables con las Dr. 21-22 del tipo Botte 3, como ilustramos en la Figura 13 b. Tanto la amplitud de la boca, como la molduración del borde, que genera un doble resalte al exterior, así como la amplitud del cuello en altura, la carena de la panza o el pivote apuntado y las dimensiones generales del envase; y detalles tales como el tipo de sellado (en cartela rectangular, con amplio desarrollo de texto), los tituli similares (en el de Zaragoza la cifra alusiva posiblemente al peso del envase vacío) o la coincidencia cronológica en época augustea son elementos concluyentes. Es más, si no fuese por la homonimia del sello IVLI.THEOPHIL con otras Pascual 1 tenderíamos a pensar, sin una autopsia directa del envase, en una filiación itálica para el ánfora cesaraugustana. Respecto a su relación con las salazones piscícolas, dicha propuesta es muy probable por analogía con la familia itálica de las Dr. 21-22, aunque se trata de una propuesta que habrá que verificar con datos empíricos en el futuro.

Es muy probable que cuestiones de carácter metodológico no favorezcan la identificación de esta forma por parte de los arqueólogos, por el momento no integrada dentro de la tipología de las ánforas tarraconenses actualmente en vigor (López Mullor y Martín 2008; cfr. las fichas de producción tarraconense en amphorae.icac.cat), a pesar de ser considerada en ámbito internacional (Rizzo 2014: nota 371).

Otro ejemplar interesante es la citada pieza altoimperial de Lucentum (Tossal de Manises), considerada como hemos visto asociable a este tipo, procedente de las antiguas excavaciones en esta importante ciudad romana -actual Alicante- (Figueras 1971: 117, no 416). Como reproducimos en la Figura 14, se trata de un ánfora claramente emparentable con esta forma, estando así inventariada en los fondos del MARQ de Alicante, donde se conserva. ${ }^{12}$ Se trata de una pieza de $90 \mathrm{~cm}$ de altura, con una amplia boca de 19,7 cm de anchura máxima, con borde en banda de sección cuadrangular, con una pared exterior sensiblemente cóncava (Figura 14). Si el ejemplar no estuviese completo su adscripción tipológica no sería fácil, confundiéndose con una Dr. 1 o con una Tarraconense 1 (Beltrán 2008: 276, fig. 2). El cuello es corto y troncocónico, separado por una acusada carena del inicio de la panza, en la cual se apoya la parte inferior

\footnotetext{
${ }^{12}$ Agradecemos muy sinceramente a M. Olcina y a A.M. García Barrachina, del MARQ, habernos suministrado toda la información relativa a este ejemplar (CS 6893; signatura: F-416 // ANF-003) durante los meses de enero y febrero de 2013, y a esta última investigadora por haber realizado el aparato gráfico que presentamos en la Figura 14, de su autoría. Procede de las excavaciones realizadas el 28 de octubre de 1935 en el área del yacimiento denominada C/ Popilio (estancia 2-1) actualmente conservada en el anforario ANF 01/A-.
} 


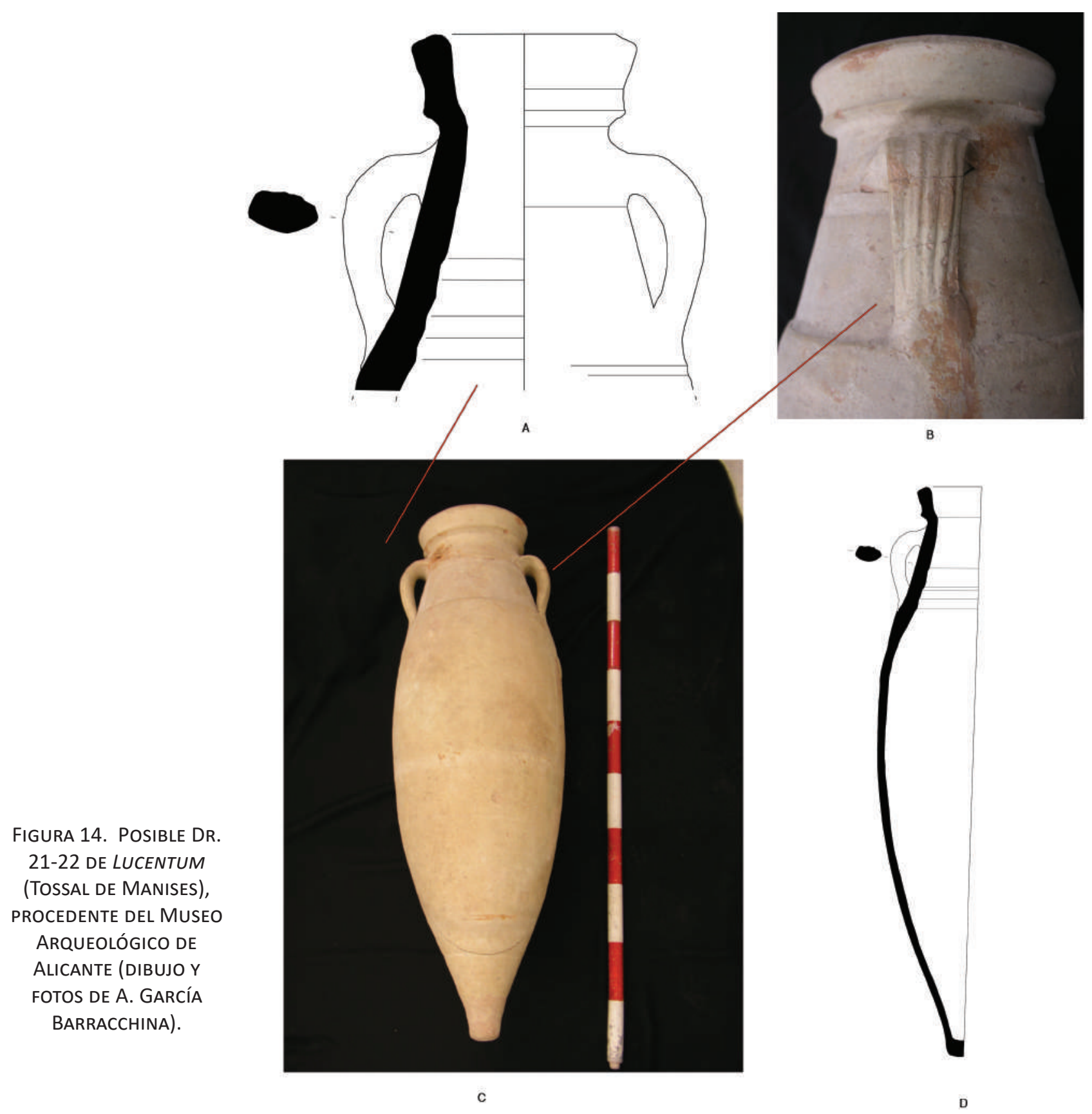

de las asas. Precisamente éstas últimas son cortas, de trayectoria elíptica y sección ovalada, con cuatro acanaladuras en su parte dorsal (Figura 14). El cuerpo es fusiforme, con $27 \mathrm{~cm}$ de anchura máxima, rematado en un pivote macizo apuntado. La pasta del ejemplar es de coloración rosa-anaranjado, con múltiples desgrasantes pequeños y medianos, identificándose en superficie mica y otras inclusiones heterométricas de color blanco y rojizo, con una coloración exterior amarillenta muy característica. No se adscribe macroscópicamente con claridad a ninguno de los grupos de pasta 'internacionales', pudiendo tratarse de una producción regional no identificada aún. No es fácil atribuir esta pieza a una producción concreta, aunque es muy probable que se trate de una manufactura tarraconense, sobre lo cual habrá que profundizar en el futuro.
Estos dos ejemplares que hemos traído a colación proceden de la tarraconense septentrional (área de Caesaraugusta) y de la zona meridional de la misma (Lucentum), augurando interesantes posibilidades de futuro en relación a la caracterización de las Dr. 21-22 de esta región, que requieren un trabajo monográfico en los próximos años.

\subsection{Balance sobre el conocimiento actual de las Dr. 21- 22: múltiples desafíos de futuro}

El estudio de las ánforas del tipo Dr. 21-22 del proyecto Impianto Elettrico de Pompeya ha servido para realizar un estado de la cuestión atlántico-mediterráneo sobre esta familia anfórica. Han sido muchos los logros de los últimos años, especialmente la tipo-cronología propuesta por E. Botte, si bien quedan muchos aspectos por precisar en el futuro -como por ejemplo la precisión 
del tipo 3, actualmente un cajón de sastre-. Un dato muy significativo al respecto es que actualmente únicamente conocemos una figlina emisora de estas formas en Italia, caso del taller de Alcamo Marina en Sicilia noroccidental (González Muro 2011; Giorgietti, González Muro y Botte 2006), no habiéndose detectado ninguno en el entorno del estrecho de Mesina o del área tirrénica, como denotan los últimos corpora (Olcese 2011-2012), lo cual augura interesantes novedades de futuro.

La revisión realizada en estas páginas ha permitido proponer una ampliación de la cronología tradicional planteada para esta forma ( 25 a.C. - 125 d.C.), tanto en la parte inicial de su intervalo como en su perduración en pleno s. II d.C., siendo la datación que planteamos entre el 75/50 a.C. y el 150/175 d.C. Son formas con seguridad anteriores a época de Augusto, al menos en el caso de aquellas producidas en los talleres de la costa del Estrecho de Gibraltar (El Rinconcillo en Algeciras y Baelo Claudia), por convivencia estratigráfica con Dr. 1A y 1C, como ya hemos indicado en el apartado correspondiente. ${ }^{13}$

No obstante, existiendo diversos focos de producción para esta forma (Lazio/Campania, Calabria, Sicilia y península ibérica), será tarea del futuro precisar la cronología en cada una de las diversas regiones productoras.

Las ánforas del tipo Dr. 21/22 han permitido poner sobre la mesa su presencia en Pompeya en un porcentaje en torno al 3,5\% del total de importaciones alimenticias en ánforas. Unas cifras muy reducidas en relación a las de otros productos haliéuticos importados, especialmente el garum y derivados del sur de Hispania. No obstante, la revisión que ha sido posible hacer de la literatura publicada indica que en otros contextos pompeyanos o itálicos estos porcentajes son similares o incluso menores. De lo cual se infiere que la presencia de pescado itálico (calabrés, siciliano y campano) era frecuente pero en porcentajes discretos o incluso inexistentes. Como hemos indicado, en el caso de las ánforas del I.E., sorprende que la mayor parte de importaciones piscícolas sean lejanas (mayoritariamente calabresas-peloritanas), y en muy menor medida del litoral tirrénico, no habiendo aparecido, por motivos que habrá que investigar en el futuro, importaciones de Sicilia occidental (área de Trápani).

Hemos incluido en este trabajo documentación inédita procedente de los estudios dirigidos por los firmantes en la Tienda del Garum de Pompeya (I, 12, 8), los cuales permiten por primera vez verificar las hipótesis

\footnotetext{
${ }^{13}$ Aun planteando las fechas más modernas, las Dr. 1 de Ulterior/Baetica se fechan actualmente entre el 140/130 y el 30/25 a.C.; las Dr. 1 de la tarraconense septentrional entre el 100/90 y el 10/1 a.C.; y la producción de Dr. 1 del Valle del Guadalquivir entre el 110/90 y el 30/25 a.C. (amphorae.icac.cat). Es incluso probable que las dataciones de C. Domergue para algunos de sus estratos puedan ser rebajadas hasta mediados del s. II a.C. para los niveles basales, como hemos propuesto en otro lugar, no habiéndose detectado en los mismos estas formas, fechados hasta el cambio de siglo (Bernal, Arévalo y Sáez 2007).
}

que atribuían a estas ánforas un contenido piscícola: los hallazgos de ictiofaunas arqueológicas (escamas, vértebras y elementos craneales) en el interior de estos envases recién vaciados y apilados en el patio trasero de esta fábrica de conservas - tienda cuando llegó la erupción pliniana en el año 79 han confirmado su relación con la salazón de pescado (aparentemente con peces de pequeño y mediano tamaño únicamente). Los restos ícticos asociados a los tipos 1, 2 y 3 de Botte, como hemos indicado, no dejan dudas sobre este particular, constituyendo por el momento la única verificación empírica existente. Los otros contenidos alternativos propuestos, sobre todo fruta según $H$. Dressel y recientemente dátiles (Di Segni 2012: 479-480), no han podido ser verificados y restan como poco probables, a verificar en cualquier caso en el futuro.

Por último, recordar que además de los tres focos de producción itálica, historiográficamente se había propuesto la existencia de una producción hispánica de Dr. 21-22. La revisión de los datos antiguos realizada en estas páginas y la aportación de nuevos datos ha permitido confirmar la propuesta de una producción de Dr. 21-22 en la Ulterior/Baetica y otra en la Tarraconense. A efectos de nomenclatura, proponemos en los próximos años hablar de Dr. 21-22 itálicas, Dr. 21-22 tarraconenses y Dr. 21/22 béticas, para clarificar su origen, como sucede habitualmente con otras formas objeto de manufactura en varias áreas del Mediterráneo (como las Dr. 1 o las 2/4, entre otras).

Resulta paradójico que las Dr. 21-22 más antiguas actualmente sean las manufacturadas en los talleres del área del Estrecho de Gibraltar (El Rinconcillo y Baelo Claudia). De ahí que en el estado actual de la investigación lo más prudente sea plantear que las ánforas itálicas de esta familia derivan de las Dr. 21-22 de la Hispania Ulterior, que cronológicamente son las primeras, al menos una o dos generaciones más antiguas. Es esta una propuesta no novedosa, planteada desde hace años, cuando se reflexionaba sobre si estas ánforas béticas eran modelos o copias: 'n'est -ce pas le type de Bélo qui a inspiré les productions italiques?' (Botte 2009c: 162). ${ }^{14}$ Es interesante la propuesta de que la actividad de los dos talleres productores de estas ánforas en el Estrecho de Gibraltar haya sido atribuida a herederos de los primeros colonos itálicos instalados en Colonia Latina Libertinorum Carteia, fundada en el 171 a.C. en la bahía de Algeciras, los cuales se habrían encargado de intensificar la actividad de las pesquerías litorales y, con ellas, la fabricación de ánforas, copiando prototipos italianos (para El Rinconcillo: Bernal y Jiménez-Camino 2004; para Baelo Claudia: Bernal, Arévalo y Sáez 2007).

\footnotetext{
${ }^{14}$ Aunque luego este mismo autor indica que lo más probable es que no sea así porque la cronología de las producciones ibéricas es casi contemporánea a las itálicas que él sitúa en epoca augustea, hipótesis que no compartimos.
} 


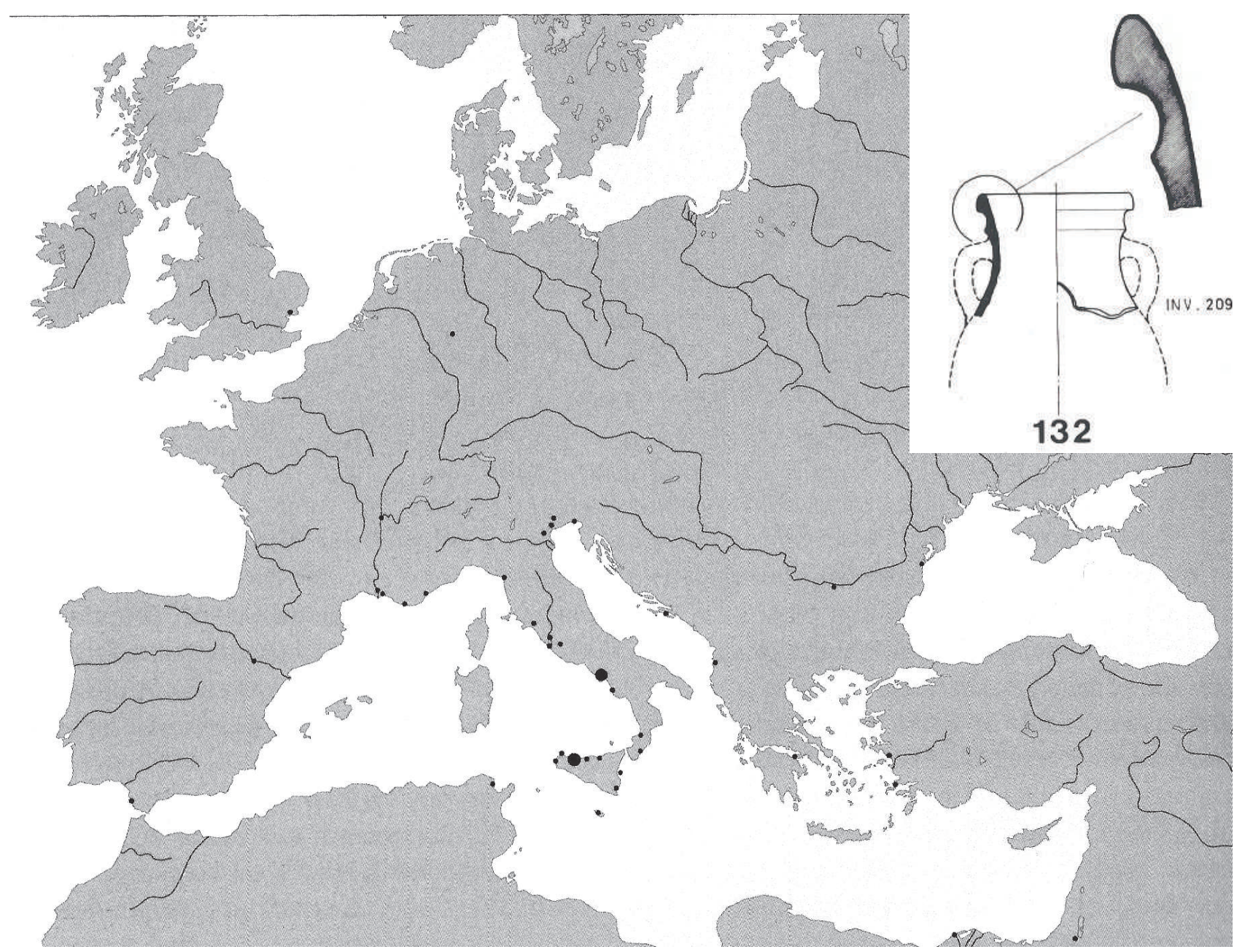

FiguRA 15. MAPA DE DISPERSIÓN DE LAS DR. 21-22 (SEgÚN BOTTE 2009B: 152, FIG. 3), y ÁNFORA DE ESTA TIPOLOGíA RECUPERAdA EN MALloRCA (CERDÀ JUAN 1980: 78 Y 82, № 132, INV. 209).

Respecto a la distribución de las Dr. 21-22 en el Mediterráneo Central y Occidental, los mapas de dispersión publicados sitúan unos mercados eminentemente occidentales (Figura 15 A) -Italia, Sicilia y sur de Francia, con cierta proyección en la Pars Orientalis (Bezeczky 2013: 126; Botte 2007: fig. 4; 2009b: 152, fig. 3) ${ }^{15}$ a los cuales debemos sumar el ánfora de Mallorca, que había pasado desapercibida hasta la fecha (Cerdà Juan 1980: 78 y $82, n^{\circ} 132$, inv. 209), y que constituye, por el momento, el hallazgo más occidental de las Dr. 21-22 itálicas (Figura $15 \mathrm{~B})$, ya que las dos situadas en la península ibérica son de producción hispanorromana.

No obstante es importante discriminar, conscientes de la existencia entre ellas de producciones occidentales, cuyo radio de exportación extra-hispánico desconocemos actualmente. ${ }^{16}$ Antes del 'boom' económico de época

\footnotetext{
${ }^{15} \mathrm{~A}$ estos hallazgos podemos sumar otros significativos como los de las Dr. 21-22 del tipo 1 en Beyruth (Reynolds 2001: 1057, fig. 1, nº 6), clasificada como bética, que verifica la exportación a la costa siriopalestina; o la presencia de Dr. 21-22 en Turris Libisonis y Cagliari, confirmando su exportación a Cerdeña (Nervi 2014: 25 y 30).

${ }^{16}$ En Italia se han publicado algunas Dr. 21-22 como occidentales por presentar la pasta blanquecina, siendo de producción calabresa-
}

augustea (con las Dr. 7/11 ampliamente atestiguadas en Italia y por supuesto en Pompeya: Manacorda 1977) únicamente ha sido posible elaborar una dispersión de ánforas salazoneras gaditanas con sellos SCG/SCET, mayoritariamente (¿o exclusivamente?) Dr. $1 \mathrm{C}$ de El Rinconcillo, la cual es ilustrativa de la importancia en la difusión de estos productos hispánicos en fechas tempranas $^{17} \mathrm{y}$, con ellos, quizás la idea de las formas asociadas.

Los mercados por tanto de las Dr. 21-22 son mucho más amplios de lo que a priori podría parecer, conscientes de que los problemas de identificación de la forma son notables en estado fragmentario -la ausencia de cuello provoca su frecuente confusión con tubuli- (Botte 2009c:

peloritana, habiendo sido confundida la pasta con las características de la Bahía de Cádiz, debido a su colorimetría blanquecino-amarillenta.

${ }^{17}$ Además de los sellos de Carteia, Baelo Claudia, Roma, Tharros y Delos (Bernal y Jiménez-Camino 2004: 603), se han sumado en los últimos años Hispalis y Jávea (Bernal, García y Sáez 2013: 366, fig. 8), a los cuales tenemos que unir ahora los documentados en Baetulo (Comas 1997: 82. № 209b), Isla Verde en Algeciras (sello inédito OP.[...] en Dr. 1C, según comunicación personal de R. Jiménez-Camino) y Tarragona (sello SCG en Dr. 1C de Tarragona, según comunicación personal de P. Berni, publicado con posterioridad en Padrós, Pujol y Sala 2015: 284, fig. 6). 

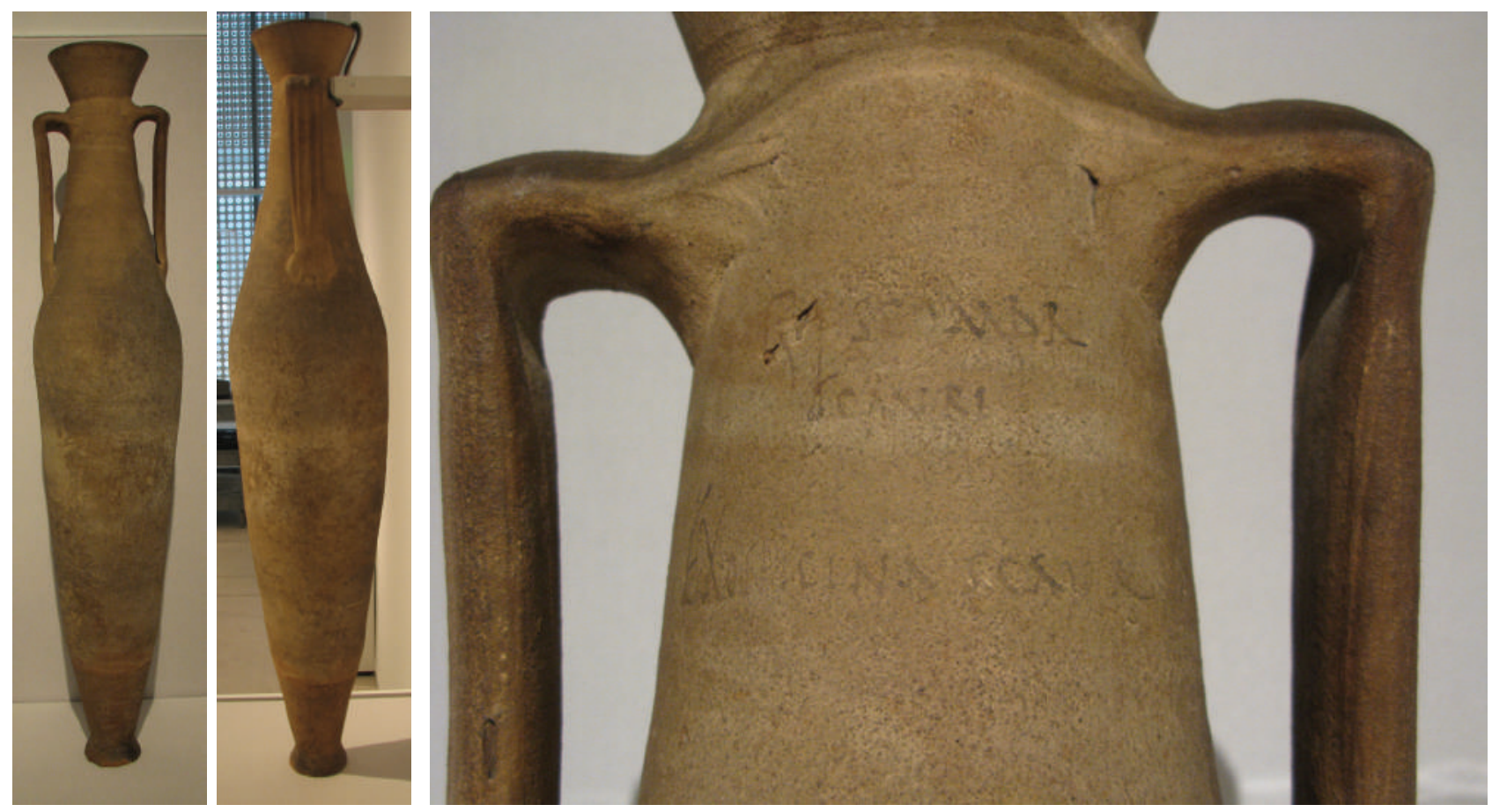

Figura 16. Ánfora RESTAURAdA DE POSIBLE PRODUCCIÓN CAMPANA PROCEDENTE DEL MUSEO DE TAMPA, CON DETALLE DEL TITULUS PICTUS (FOTOS R. CURTIS).

121), lo que podría modificar la imagen actual en los próximos años. Un ejemplo de ello se refleja claramente en el reciente estudio de las ánforas documentadas en la Casa de las Vestales de Pompeya (De Sena e Ikaheimo 2003: Table 1) -infravalorado por un NMI determinado por EVE y no por no máximo de bordes/fondos-: en este estudio no se habla específicamente de las salazones itálicas en Dr. 21-22, tratándose únicamente las africanas, tripolitanas, béticas y lusitanas, planteando explícitamente sobre las salazones itálicas que restan 'While a fair amount of central Italian olive oil and fish products consumed in Pompeii were produced in Italy, there is no trace of such commodities in the ceramic record of the city' (De Sena e Ikaheimo 2003: table 4; 313). Un interesante campo de trabajo, por tanto, para el futuro.

Un último aspecto que planteamos a la hora de realizar este trabajo y que no hemos podido acometer por falta de información al respecto es sobre la presencia de otras salsas de pescado itálicas en Pompeya. Recientemente se han identificado ánforas noritálicas -anforette tipo Grado- con salazones piscícolas (Auriemma y Pesavento 2009), e incluso la existencia de algunas ánforas Dr. 6 adriáticas reutilizadas para la elaboración de salsas piscícolas (Mazzocchin y Wilkens 2013). No obstante, este tipo de envases no han sido identificados aún en Pompeya, al menos de manera explícita, mermando con ello las posibilidades de evaluar, a corto plazo, los intercambios intra-provinciales, sobre lo cual habrá que volver en los próximos años.

Como también será importante en el futuro valorar la exportación del conocido garum pompeianum (Étienne y
Mayet 1998), además del envasado en los conocidos urcei de Aulus Umbricius Scaurus (recientemente Cappelleto et al. 2013), los cuales estaban destinados a mercados regionales pero que sabemos que en contadas ocasiones viajaban, como ilustran los ejemplos de Roma (Rizzo 2003: 149 y 188, tav. XXXIV, ํำ172). En este contexto traemos a colación un ánfora conservada en el Tampa Museum of Art, de tipología indeterminada (Figura 16), relacionada con los menesteres haliéuticos debido al titulus pictus que presenta: G(ari) F(los) Scombri(i)/Scauri/Ex officina Scaur(i) (Curtis 2014: 104-105). Este ejemplar ha sido identificado como una posible imitación pompeyana de una Dr. 12 hispánica, a la cual se le reintegró el pie erróneamente en época moderna ${ }^{18}$ (Curtis 2014: 105, nota 44). Se trata de una interesante pieza, de la cual habrá que intentar localizar paralelos en los próximos años, tratándose quizás de otro tipo de ánfora en la cual se comercializaron las conocidas salsas piscícolas vesubianas, no identificadas hasta la fecha.

Por último, aclarar que las Dr. 21-22, especialmente en la bibliografía italiana, han sido consideradas como los cadi citados por las fuentes clásicas para la comercialización de fruta en conserva y otros productos como la pez (un ejemplo en Toniolo 1991): recientemente se ha reestudiado esta cuestión, atribuyendo a otros envases no anfóricos esta denominación (Cavassa 2008) y clarificando por ello el panorama.

\footnotetext{
${ }^{18}$ No olvidemos que se trata de una pieza procedente de la Joseph Veach Noble collection 1986.131 (Murray 1985: 51), por lo que no debe extrañar su reconstrucción.
} 
Como se ha podido comprobar a lo largo de estas páginas, restan muchas perspectivas de estudio para los próximos años en torno a esta singular familia anfórica.

\section{Bibliografía}

Auriemma, R. 2000. Le anfore del relitto di Grado e il loro contenuto. Mélanges de l'Ecole française de Rome. Antiquité 112, $\mathrm{n}^{\circ} 1$ : 27-51.

Auriemma, R. y S. Pesavento 2009. I tituli picti delle anfore di Grado, en Olio e Pesce in epoca romana. Produzione e commercio nelle regioni dell'Alto Adriatico. Antenor Quaderni 15: 275-280. Padua.

Beltrán Lloris, M. 1970. Las ánforas romanas en España. Zaragoza.

Beltrán Lloris, M. 2008. Las ánforas tarraconenses en el valle del Ebro y la parte occidental de la provincia tarraconense, en A. López y X. Aquilué (coord.) La producció $i$ el comerç de les àmfores de la Provincia Hispania Tarraconensis. Homenatge a Ricard Pascual $i$ Guasch. Monografies 8: 271-317. Barcelona: MAC.

Beltrán Lloris, M. 2014. Iulius Teophilus. Un nuevo fabricante de salazones tarraconenses en época de Augusto, en A. Capalvo Liesa (coord.) Miscelánea de estudios en homenaje a Guillermo Fatás Cabeza: 143-153. Zaragoza.

Bernal Casasola, D., A. Arévalo, A. Morales y E. Roselló 2007. Un ejemplo de conservas de pescado baelonenses en el siglo II a.C., en A. Arévalo y D. Bernal (eds) Las cetariae de Baelo Claudia. Avance de las investigaciones arqueológicas en el barrio industrial (2000-2004). Monografías de Arqueología, Junta de Andalucía: 355374. Sevilla.

Bernal, D., A. Arévalo, A. Muñoz, J.A. Expósito, J.J. Díaz, J. Lagóstena, J.M. Vargas, M. Lara, E. Moreno, A.M. Sáez y M. Bustamante 2013. Las termas y el suburbium marítimo de Baelo Claudia. Avance de un reciente descubrimiento. ONOBA 01. Revista de Arqueología y Antigüedad 0 (1): 115-152.

Bernal, D., A. Arévalo y A.M. Sáez 2007. Nuevas evidencias de la ocupación en época republicana (s. II - I a.C.), en A. Arévalo y D. Bernal (eds), Las cetariae de Baelo Claudia. Avance de las investigaciones arqueológicas en el barrio industrial (2000-2004). Monografías de Arqueología: 237-353. Sevilla: Junta de Andalucía.

Bernal, D. y D. Cottica, D. (coord.) 2012. Memoria definitiva del proyecto 'El Garum de Pompeya y Herculano. Explotación de los recursos del mar en ámbito vesubiano'. IV campaña (2011-2012). Original inédito depositado en la SAP Pompeya- y en el IPCE -Madrid-.

Bernal Casasola, D., D. Cottica, M. Bustamante, J.J. Díaz, J.A. Expósito, E. García, A. Gómez, S. Landi, M. Lara, L. Lorenzo, R. Marlasca, J.A. Riquelme, C.G. Rodríguez, A.M. Sáez Romero, J.M. Vargas y J. Verdugo 2012. Pesca y Garum en Pompeya y Herculano. Cuarta campaña arqueológica (2011), en Informes y Trabajos. Excavaciones arqueológicas en el exterior 09: 322-338. Madrid: Ministerio de Educación, Cultura y Deporte.

Bernal, D., D. Cottica, E. García-Vargas, L. Toniolo, C.G.
Rodríguez Santana, C. Acqua, R. Marlasca, A.M. Sáez, J.M. Vargas, F. Scremin y S. Landi 2014a. Un contexto excepcional en Pompeya: la pila de ánforas de la Bottega del Garum (I, 12, 8). Avance d un estudio interdisciplinar, en Rei Cretariae Romanae Favtorvm Acta 43: 219-232.

Bernal Casasola, D., D. Cottica, A.M. Sáez Romero, M., Bustamante y L. Toniolo 2014b. Il progetto 'Dalla pesca al Garum: lo sfruttamento delle risorse del mare nell'area vesuviana -2008/2012-. Una collaborazione italo-spagnola, en A. Arévalo, D. Bernal y D. Cottica (eds) Ebusus y Pompeya, ciudades marítimas. Testimonios monetales de una relación. Monografías del Proyecto Pesca y Garum en Pompeya y Herculano, 1: 29-59. Madrid-Cádiz Bernal Casasola, D., D. Cottica y A.P. Zaccaria 2008. El garum de Pompeya y Herculano (2008-2012). Síntesis de la primera campaña del proyecto hispano-italiano, en Informes y Trabajos 3. Excavaciones en el exterior 2008: 125-137. Madrid: Ministerio de Cultura.

Bernal Casasola, D., D. Cottica y A.P. Zaccaria 2010. Pesca y garum en Pompeya y Herculano. Síntesis de la segunda campaña del proyecto de investigación (2009), en Informes y Trabajos 5. Excavaciones en el exterior 2009: 138-149. Madrid: Ministerio de Cultura.

Bernal Casasola, D., D. Cottica y A.P. Zaccaria 2011. Pesca y Garum en Pompeya y Herculano. Actividades arqueológicas en la tercera campaña del proyecto (2010), en Informes y Trabajos 7. Excavaciones en el exterior 2010: 188-194. Madrid: Ministerio de Cultura.

Bernal Casasola, D., E. García-Vargas y A.M. Sáez 2013. Ánforas itálicas en la Hispania meridional, en G. Olcese (ed.) Immensa Aequora workshop. Ricerche archeologiche, archeometriche $e$ informatiche per la ricostruzione dell'economia e dei commerci nel bacino occidentale del Mediterraneo (metà IV sec. a.C. - I sec. d.C.): 351-372. Roma.

Bernal Casasola, D. y R. Jiménez-Camino 2004. El taller de El Rinconcillo en la Bahía de Algeciras. El factor itálico y la economía de exportación (ss. I a.C. - I d.c.), en D. Bernal y L. Lagóstena (eds) Figlinae Baeticae. Talleres alfareros y producciones cerámicas en la Bética romana (ss. II a.C. - VII d.C.) (BAR International Series 1266): 589606. Oxford.

Bezeczky T. 2006. Consumer behaviour in the first century B.C., en D. Malfitana, J. Poblome y J. Lund (eds) Old pottery in a new century. Innovating perspectives on Roman pottery studies: 287-308. Catania

Bezeczky, T. 2013. The amphorae of Roman Ephesus, Forschungen in Ephesos XV, 1. Viena.

Botte, E. 2004. Recherches sur les amphores Dressel 21-22: premiers éléments pour une nouvelle typologie. Mémoire de DEA (Université Lumière-Lyon 2), J.-Y. Empereur dir.

Botte, E. 2007. Les amphores Dressel 21-22 de Pompei. Quaderni di Studi Pompeiani 1: 169-186.

Botte, E. 2008. Les salaisons de poissons de Cumes (Italie) au premier siècle de notre ère : une nouvelle inscription peinte sur amphore Dressel 21/22, en J. Napoli (ed.) Ressources et activités maritimes des peuples 
de l'Antiquité. Les Cahiers du Littoral 2, nº 6: 443-446. Boulogne-sur-mer.

Botte, E. 2009a. A case-study. The amphorae Dressel 21 and the trade of the Sicilian salted fish in the Early Empire, en FACTA. A Journal of Roman Material Culture Studies 2 (2008): 159-169.

Botte, E. 2009b. Le Dressel 21-22, anfore da pesce tirreniche dell'Alto Impero, en Olio e Pesce in epoca romana. Produzione e commercio nelle regioni dell'Alto Adriatico. Antenor Quaderni 15: 149-171. Padua.

Botte, E. 2009c. Salaisons et sauces de poissons en Italie du Sud et en Sicile durant l'Antiquité. Collection du Centre Jean Bérard 31. Nápoles.

Botte, E. 2013. L'exportation du thon sicilien à l'époque tardo-républicaine. MEFRA 124/2 - 2012: 577-612.

Callender, M.H. 1965. Roman Amphorae. Londres.

Capelli, C., R. Cabella y M. Piazza 2009. Appendice. Analisi in sezione sottile di anfore Dressel 21-22, en Olio e Pesce in epoca romana. Produzione e commercio nelle regioni dell'Alto Adriatico. Antenor Quaderni 15: 164-168. Padua.

Cappelleto, E., D. Bernal, D. Cottica, M. Bustamante, M. Lara y A.M. Sáez (2013) Urcei per salse di pesce da Pompei - Ercolano: una prima analisi, en D. Bernal, L.C. Juan, M. Bustamante, J.J. Díaz y A.M. Sáez (eds) Hornos, talleres y focos de producción alfarera en Hispania: 271-280. Cádiz.

Cavassa, L. 2008. Les kadoi à poix du Bruttium. MEFRA 120/1: 99-107.

Cerdá Juan, D. 1980. La nave romano-republicana de la Colonia de Sant Jordi (Ses Salines - Mallorca). Palma de Mallorca.

Chacón, C., A. Arancibia y A.M. Sáez Romero e.p. Avance del estudio de la producción cerámica del alfar de Carranque a partir de los resultados de las recientes excavaciones en la Avenida Juan XXIII de Málaga, en III Congreso Internacional de la SECAH - Ex Officina Hispana «Amphorae ex Hispania. Paisajes de producción y consumo» (Universitat Rovira i Virgili, Tarragona, 1013 diciembre 2014).

Comas I Solà, M. 1997. Baetulo. Les marques d'àmfora. Badalona.

Curtis, R. 2014. From fish to fish sauce: seafood in the Ancient Roman world, en S.D. Pevnick (ed.) Poseidon and the sea. Myth, Cult and daily life: 95-109. Londres.

De Sena, E. y J. Ikaheimo 2003. The Supply of AmphoraBorne Commodities and Domestic Pottery in Pompeii 150 BC-AD 79: Preliminary Evidence from the House of the Vestals. European Journal of Archaeology 6.3: 301-321.

Di Segni, L. 2012. 1098. Latin and Greek dipinti on imported amphorae, 1 c. BCE - early I c. CE, en AA.VV. (eds) Corpus Inscriptionum Iudaeae/Palaestinae, I, 2, Jerusalem: 479-480. De Gruyter.

Díaz Rodríguez, J.J. 2014. Los alfares romanos en Hispania (ss. II a.C. - VII d.C.): Sistematización de la documentación del conventus Gaditanusy análisis comparativo interprovincial. Tesis Doctoral inédita, Universidad de Cádiz.

Domergue, C. 1973. Belo I. La stratigraphie. París.

Dressel, H. 1879. Di un grande deposito di anfore rinvenuto nel nuovo quartiere del Castro Pretorio. Bulletino Comunale 39-112: 143-196.
Éttiene, R.y F. Mayet 1994. A propos de l'amphore Dressel 1C de Belo. Mélanges de la Casa de Velázquez XXX, 1: 131-138.

Éttiene, R. y F. Mayet 1998. Le garum a Pompéi. Production et commerce. REA 100: 199-215.

Éttiene, R. y F. Mayet 2002. Salaisons et sauces de poisson hispaniques. París.

Fernández Cacho, S. 1995. Excavaciones arqueológicas en El Rinconcillo (Algeciras, Cádiz). Anuario Arqueológico de Andalucía 1992, tomo III: 70-77.

Fernández Cacho, S. 1997. Informe arqueológico de la ejecución de obras en el complejo "Residencial Monteverde" (Algeciras, Cádiz). Original depositado en la Delegación de Cultura de la Junta de Andalucía, Cádiz.

Ferrandes, A.F. 2008. I contenitori da trasporto, en F. Filippi (ed.) Horti et sordes. Uno scavo alle falde del Gianicolo: 247-283. Roma.

Figueras Pacheco, F. 1971. Relación de hallazgos arqueológicos en el Tossal de Manises (Alicante), 1933-1935. Serie maior, XIII. Alicante: Publicaciones del fondo editorial del Excmo. Ayuntamiento de Alicante.

García Vargas, E., R. De Almeida y H. González Cesteros 2011. Los tipos anfóricos del Guadalquivir en el marco de los envases sudhispanos del siglo I a.C. Un universo heterogéneo entre la imitación y la estandarización. Spal 20: 185-283.

Giorgetti, D., X. González Muro y E. Botte 2006. Nouvelles considérations sur la Production d'amphores Dressel 21-22. L'atelier d'Alcamo Marina (Trapani, Sicile), en SFECAG. Actes du Congrès de Pézenas: 505-516.

González Muro, X. 2011. Le anfore, en D. Giorgetti y X. González (a cura di) Le fornaci romane di Alcamo. Rassegna di studi e Ricerche 2006/2008. Catalogo dei Materiali: 99-116. Imola.

Grimaldi, M., P. Buondonno, A. Carannante, R. Ciardiello, A. Colucci, A. Cotugno, A. De Luca, D. Di Domenico, M.L. Fatibene, F. Fuschino, M. Giorleo, R. Luongo, L. Pisano, I. Picillo, A. Russo, F. Schiano Lomoriello, G. Tabacchini y G. Trojsi 2011. La casa di Marco Fabio Rufo. Lo scavo del giardino e i materiali (www. fastionline.org/docs/FOLDER-it-2011-217.pdf).

López Mullor, A. y A. Martín 2008. Las ánforas de la Tarraconense, en D. Bernal y A. Ribera (eds) Cerámicas hispanorromanas. Un estado de la cuestión: 689-724. Cádiz.

Manacorda, D. 1977. Anfore spagnole a Pompei, en L'Instrumentum domesticum di Ercolano e Pompei nella prima età imperiale. Quaderni di cultura materiale 1: 121133. Roma.

Manacorda, D. 1989. Le anfore dell'Italia republicana, en Amphores romaines et histoire économique. Collection de l'École Française de Rome 114: 443-467. Roma.

Marlasca, R. y C.G. Rodríguez Santana 2011. Análisis arqueozoológico del paleocontenido de dolia y ánforas de Pompeya, en D. Bernal, D. Cottica y A. Zaccaria (coord.) Memoria definitiva del proyecto 'El garum de Pompeya y Herculano. Explotación de los recursos del mar en ámbito vesubiano'. II Campaña (2009). Original inédito depositado en la SAP (Pompeya) y en el IPCE (Madrid): 204-228. 
Mazzocchin, S. y B. Wilkens 2013. Fish and crustaceans from a Roman amphora in northern Italy. Archaeofauna 22: 105-111.

Murray, S. 1985. Collecting the Classical Past: Antiquities from the Joseph Veach Noble Collection. Tampa.

Nervi, C. 2014. La Sardinia tra penisola ibérica e Africa immersa in un mare di sale -I d.C. - VII d.C., en Fish and Ships. Production et commerce des salsamenta durant l'Antiquité: 199-212. Aix-en-Provence.

Olcese, G. 2011-2012. Atlante dei siti di produzione cerámica (Toscana, Lazio, Campania e Sicilia) con le tabelle dei principali relitti del Mediterraneo occidentale con carichi dall'Italia centro meridionale (IV secolo a.C. - I secolo d.C.). Immensa Aequora 2. Roma: Edizioni Quasar.

Padrós, C., A. Pujol y R. Sala 2015. Puig Ciutat (Oristà, Barcelona): un praesidium pompeià als peus dels Pirineus? Revista d'Arqueologia de Ponent 25: 279-292.

Palaczyk, M. 2014. Können transportamphoren etwas über 'Social Identity' aussagen? Fallbeispiel der amphoren Dressel 21-22 vom Monte Iato, en Rei Cretariae Romanae Favtorvm Acta 43: 581-588.

Panella, C. 2002. Le anfore di età imperiale nel Mediterraneo occidentale, en Céramiques héllenistiques et romaines 3. Publications du Centre Camille-Julien 28: 177-275.

Panella, C. y M. Fano 1977. Le anfore con anse bifide conservate a Pompei: contributo ad una loro classificazione, en Méthodes classiques et méthodes formelles dans l'étude des amphores. Collection de l'École Française de Rome 32: 133-177. Roma.

Parker, A.J. 1992. Ancient shipwrecks of the Mediterranean and the Roman provinces. BAR international series 580 . Oxford.

Pascual, G. y A. Ribera 2007. De Oriente a Occidente. El consumo de productos foráneos, en A. Ribera, M. Olcina y C. Ballester (eds) Pompeya bajo Pompeya. Las excavaciones valencianas en la casa de Ariadna: 120-123. Valencia.

Pascual, G. y A. Ribera 2014. Ánforas tardopúnicas sicilianas en Pompeya, en Rei Cretarice Romance Favtorvm Acta 43: 461-466.

Peacock, D.P.S. y D.F. Williams 1986. Amphorae and the Roman Economy. An introductory Guide. Londres y Nueva York.

Piton, J. y D. Djaoui 2009. Les amphores du Rhône: des origines multiples, en L. Long y P. Picard (eds) César. Le Rhône pour mémoire: 263-273. Arlés.

Ramon Torres, J. 1995. Las ánforas fenicio-púnicas en el Mediterráneo Central y Occidental. Col.lecció Instrumenta 2. Barcelona.

Reynolds, P. 2001. Baetican, lusitanian and tarraconensian amphorae in Classical Beyruth: some preliminary observations of trends in amphora imports from the western Mediterranean in the Anglo-Lebanese Excavations in Beyruth (BEY 006, 007 and 045), en Congreso Internacional Ex Baetica Amphorae, III: 10351060. Écija.

Ribera, A. 2007. El instrumentum domesticum en época samnita y romana", en A. Ribera, M. Olcina y C.
Ballester (eds) Pompeya bajo Pompeya. Las excavaciones valencianas en la casa de Ariadna: 110-115. Valencia.

Rivet, L. 2010. Recherches archéologiques au coeur de Forum Iulii. Les fouilles dans le groupe episcopal de Fréjus et à ses abords (1979-1989). Bibliothèque d'Archéologie Méditerranéenne et Africaine 6. Aix-en-Provence.

Rizzo, G. 2003. Instrumenta Urbis I. Ceramiche fini da mensa, lucerne ed anfore a Roma nei due primi secoli dell'Imperio. Collection de l'École Française de Rome 307. Roma.

Rizzo, G. 2014. Le anfore, Ostia e i commerci mediterranei, en Ostia VI. Le Terme del Nuotatore. Studi Miscellanei 38: 65-481. Roma: L'Erma.

Rodríguez Santana, C.G. y R. Marlasca 2011. Análisis y estudio de las ictiofaunas arqueológicas de Pompeya y Herculano (Nápoles, Italia). Informe inédito resultado del convenio Universidad de Cádiz - Cabildo de Gran Canaria. Gáldar.

Sciallano, M. y P. Sibella 1991. Amphores. Comment les identifier? Aix-en-Provence: Édisud.

Scotti, C. 1984. Le anfore, en M. Bonghi Jovino (ed.) Ricerche a Pompei. L'Insula 5 della Regio VI dalle origini al 79 d.C.: 270-317. Roma: L'Erma di Bretschneider.

Stefani, G. y M. Borgongino 2005. Civus, en Cibi e sapori a Pompeie dintorni. SAP: 65-94. C. Mare di Stabia: Edizione Flavius.

Timby, J. 2004. Amphorae from excavations at Pompeii by the University of Reading, en J. Eiring y J. Lund (eds) Transport amphorae and trade in the Eastern Mediterranean. Acts of the International Colloquium at the Danish Institute at Athens (2002). Monographs of the Danish Institute at Athens 5: 383-392. Aarhus.

Toniolo, A. 1991. Le anfore di Altino. Archeologia Veneta XIV. Padua.

Tremoleda I Trilla, J. 2000. Industria y artesanado cerámico de época romana en el nordeste de Cataluña (época augustea y altoimperial). British Archaeological Reports, I.S. 835. Oxford.

University of Southampton 2014. Roman Amphorae: a digital resource [data-set]. York: Archaeology Data Service [distributor] (doi:10.5284/1028192).

Zevi, F. 1966. Appunti sulle anfore romane. Archeologia Classica 18/2: 207-247. 